ARTICLE

\title{
Epigenetic homogeneity in histone methylation underlies sperm programming for embryonic transcription
}

\author{
Mami Oikawa 1,2,9, Angela Simeone 1,2,9, Eva Hormanseder 1,2, Marta Teperek (1) 1,2, Vincent Gaggioli,2, \\ Alan O'Doherty (1) ${ }^{3}$, Emma Falk (1) ${ }^{4}$, Matthieu Sporniak (10 ${ }^{4}$, Clive D'Santos ${ }^{5}$, Valar Nila Roamio Franklin ${ }^{5}$, \\ Kamal Kishore ${ }^{5}$, Charles R. Bradshaw (10) 1,2, Declan Keane ${ }^{6}$, Thomas Freour (1) 7, Laurent David (1) ${ }^{4}$, \\ Adrian T. Grzybowski ${ }^{8}$, Alexander J. Ruthenburg (10 ${ }^{8}$, John Gurdon ${ }^{1,2}$ \& Jerome Jullien 1,2,4凶
}

Sperm contributes genetic and epigenetic information to the embryo to efficiently support development. However, the mechanism underlying such developmental competence remains elusive. Here, we investigated whether all sperm cells have a common epigenetic configuration that primes transcriptional program for embryonic development. Using calibrated ChIP-seq, we show that remodelling of histones during spermiogenesis results in the retention of methylated histone $\mathrm{H} 3$ at the same genomic location in most sperm cell. This homogeneously methylated fraction of histone $\mathrm{H} 3$ in the sperm genome is maintained during early embryonic replication. Such methylated histone fraction resisting post-fertilisation reprogramming marks developmental genes whose expression is perturbed upon experimental reduction of histone methylation. A similar homogeneously methylated histone $\mathrm{H} 3$ fraction is detected in human sperm. Altogether, we uncover a conserved mechanism of paternal epigenetic information transmission to the embryo through the homogeneous retention of methylated histone in a sperm cells population.

\footnotetext{
${ }^{1}$ Wellcome Trust/Cancer Research UK Gurdon Institute, University of Cambridge, Tennis Court Road, Cambridge CB2 1QN, UK. ${ }^{2}$ Department of Zoology, University of Cambridge, Downing Street, Cambridge CB2 3EJ, UK. ${ }^{3}$ UCD School of Agriculture and Food Science, University College Dublin, Dublin 4 D0 4 V1W8, Ireland. ${ }^{4}$ CRTI, INSERM, UNIV Nantes, Nantes, France. ${ }^{5}$ Cancer Research UK Cambridge Institute, University of Cambridge, Robinson Way, Cambridge CB2 ORE, UK. ${ }^{6}$ ReproMed Ireland, Rockfield Medical Campus, Northblock, Dundrum, Dublin 16 D16 W7W3, Ireland. ${ }^{7}$ Service de Biologie de la Reproduction, CHU Nantes, Nantes, France. ${ }^{8}$ Department of Molecular Genetics and Cell Biology, The University of Chicago, 920 East 58 th Street, Chicago, IL 60637, USA. ${ }^{9}$ These authors contributed equally: Mami Oikawa, Angela Simeone. ${ }^{凶}$ email: jerome.jullien@inserm.fr
} 
F ertilisation of eggs by sperm produces embryos with much higher efficiency than embryos generated by other methods, such as nuclear transfer ${ }^{1}$. What is the basis for such a high developmental potential of sperm? Previously we and others have shown that spermatids, the immediate precursors of sperm, with the same haploid genetic content but with a different chromatin structure, have a reduced ability to support embryonic development ${ }^{2-4}$. Hence, beside the delivery of the paternal genetic material, sperm also deliver epigenetic cues that are necessary for embryonic development. Such epigenetic features from the sperm have been proposed to participate in normal embryonic development through the regulation of gene expression in early embryos. This hypothesis is based on the observation that in mammals, zebrafish and frogs, developmentally important genes are marked by modified histones in sperm, a feature that correlates with their expression in the early embryos $^{5-8}$. Importantly, global interference with sperm histone methylation during either spermiogenesis or at fertilisation appears to alter embryonic gene expression and development ${ }^{2,9}$. This suggests that modified histones in sperm chromatin are required for embryonic development.

In order to understand the importance of the epigenetic contribution of sperm to embryos, it is crucial to evaluate the homogeneity of chromatin composition between single-sperm cells. Indeed, intra cytoplasmic sperm injection to eggs demonstrated that almost every sperm cell, regardless of its ability to fertilise an egg, is competent to support development ${ }^{10}$. This implies that sperm-derived epigenetic features required for proper embryonic gene regulation must be present in every sperm cell of a population (i.e., homogeneous). The question of homogeneity in sperm chromatin composition is particularly important with regards to modified histones. Indeed, spermiogenesis is associated with a massive rearrangement of chromatin that entails loss of histones and deposition of protamines ${ }^{11}$. In mammals in particular, only $0.3-10 \%$ of histones found in somatic cells are retained in mature sperm ${ }^{5,12,13}$. Because of this loss, it has not been possible to clearly distinguish whether some histones are always retained at the same position in the genome of most sperm cells and hence could transmit epigenetic information, or if they are randomly distributed and are therefore unlikely to carry important epigenetic information ${ }^{14,15}$. Addressing this question of epigenetic homogeneity in sperm is therefore crucial, as it will establish whether modified histones have the required attributes to participate in a faithful transmission of epigenetic information from the sperm to the embryo.

In Xenopus laevis, the deposition of protamines during spermiogenesis is associated with only a partial loss of some of the core histones ${ }^{16,17}$. This feature places this vertebrate in an intermediate position between the situation found in mammals, where the majority of histones are replaced, and zebrafish in which sperm do not lose any histones ${ }^{5,7}$. Taking advantage of this unique feature of Xenopus laevis spermiogenesis in combination with a recently developed quantitative ChIP technology ${ }^{18}$, we are able to provide a detailed analysis of histone and modified histone distribution on chromatin in a sperm population. We show that during spermiogenesis, the programming of sperm genes for embryonic development is associated with the formation of chromatin regions of homogeneous epigenetic constitution within a sperm population. Finally, we provide evidence of homogeneous histone methylation in human sperm, suggesting a conservation of sperm epigenetic programming mechanisms between vertebrates.

\section{Results}

Packaging of Xenopus sperm chromatin by histones. Sperm core histones and their associated post-translational modifications are potential carriers of epigenetic information instructive for orchestrating embryonic gene expression. A prerequisite for such core histone involvement in the epigenetic programming of sperm for development is their presence at the same genomic location in most sperm cells. We therefore evaluated how and where core histones package the chromatin in sperm. We first analysed sperm chromatin core histone composition. Using quantitative western blotting, we found that the content of histone $\mathrm{H} 3$ and $\mathrm{H} 4$ in $\mathrm{X}$. laevis sperm is comparable to that of somatic cell, whereas that of histone $\mathrm{H} 2 \mathrm{~A}$ and $\mathrm{H} 2 \mathrm{~B}$ decreases by $\sim 60-70 \%$ (Fig. 1a) as previously reported ${ }^{17}$. This raises the question of how core histones are associated with sperm DNA in X. laevis. Indeed, the stoichiometry of core histones retained in frog sperm implies that a large fraction of histone $\mathrm{H} 3 / \mathrm{H} 4$ cannot be associated with DNA as nucleosomes. To reveal how DNA is packaged with the core histones retained in frog sperm, we performed a micrococcal nuclease (MNase) digestion assay, as described before ${ }^{2}$.

Similar to what is observed in somatic cells, MNase treatment of sperm chromatin generated $150 \mathrm{bp}$ fragments corresponding to nucleosomes (Fig. 1b). Two additional DNA fragments with a size of $\sim 70$ and $\sim 110$ bp appear specifically after digestion of sperm chromatin. Such shorter DNA fragments could potentially correspond to MNase getting access to the DNA wrapped around nucleosomes and leading to an internal cut by the nuclease (Fig. 1c). Alternatively, shorter fragments could arise from protection of the DNA by different nucleoprotein complexes altogether. To distinguish between these two possibilities, we used sucrose gradient centrifugation to separate DNA-protein complexes (hereafter named particles) according to their size. The 70, 110 , and 150 bp DNA fragments are recovered at gradually lower position on the gradient, clearly indicating that these DNA fragments are present in nucleoprotein complex of increasing size (Fig. 1d). To elucidate the composition of these particles we performed quantitative mass spectrometry (tandem mass tag, TMT) on proteins collected from the sucrose gradient fractions containing the 150 or 70 bp DNA fragments, in four biological replicates. The $110 \mathrm{bp}$ particles were excluded from the analysis as we could not isolate a fraction containing only these types of DNA fragments. Using this approach, we identified 840 proteins associated with the purified chromatin particles (Supplementary Data 1). Relative abundance of proteins associated with the $150 \mathrm{bp}$ versus 70b bp DNA was evaluated after normalisation to histone H4 signal. Both DNA complexes show similar association with core histones H3, H3.3 as well as linker histones and HMGN1-3 proteins $(|\log \mathrm{FC}(150 / 70)|<1.5$ and $\mathrm{FDR}>0.05)$. Interestingly, compared with the $70 \mathrm{bp}$ DNA, the $150 \mathrm{bp}$ DNA is enriched for all known variants of core histone $\mathrm{H} 2 \mathrm{~A}$ and $\mathrm{H} 2 \mathrm{~B}(\operatorname{logFC}(150 / 70)>$ 1.5 and FDR $<0.05)$. By contrast, the $70 \mathrm{bp}$ particles show increased association with testis-specific histone $\mathrm{H}_{1} \mathrm{FX}^{19}$ and protamine (sperm basic protein $5^{20}$ ) as well as numerous proteins involved in chromatin structure such as CBX3 (also known as HP1gamma), HMGB1-3, HMGA2, WDR5 and WDR16 (logFC $(150 / 70)<-1.5$ and FDR $<0.05)$. We confirmed by western blot analysis that the $70 \mathrm{bp}$ fragments contain a lower ratio of $\mathrm{H} 2 \mathrm{~A}$ and $\mathrm{H} 2 \mathrm{~B}$ to $\mathrm{H} 3$ and $\mathrm{H} 4$ as that found in the nucleosome particles (150 bp fragments), as well as a higher ratio of HMGB1 to H4, and a similar ratio of HMGN2 to H4 (Fig. 1e and Supplementary Fig. 1). These data show that the 110 and 70 bp fragments do not correspond to nucleosomes formed of core histone octamers, but rather correspond to DNA fragments protected from MNase digestion by core histone complexes depleted of $\mathrm{H} 2 \mathrm{~A}$ and $\mathrm{H} 2 \mathrm{~B}$ possibly as $(\mathrm{H} 3 / \mathrm{H} 4)_{2}$ tetramers $(70 \mathrm{bp})$ or $(\mathrm{H} 3 / \mathrm{H} 4)_{2}(\mathrm{H} 2 \mathrm{~A} / \mathrm{H} 2 \mathrm{~B})$ hexamers (110 bp) (Fig. if and refs. ${ }^{21,22}$ ).

From these analyses, we conclude that Xenopus laevis sperm DNA has a similar density of histone $\mathrm{H} 3$ and $\mathrm{H} 4$ as a somatic cell. However, in sperm, these two core histones are packaging DNA 
a

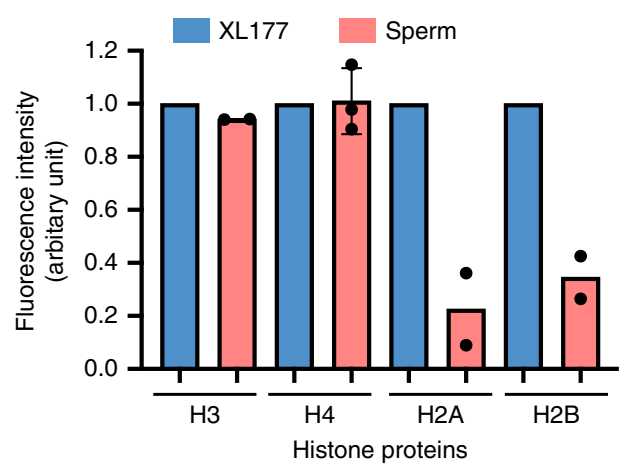

b

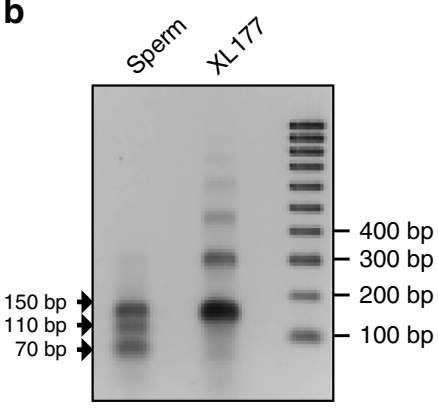

C

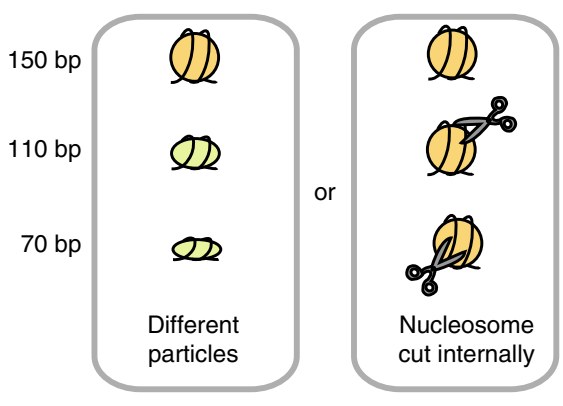

d

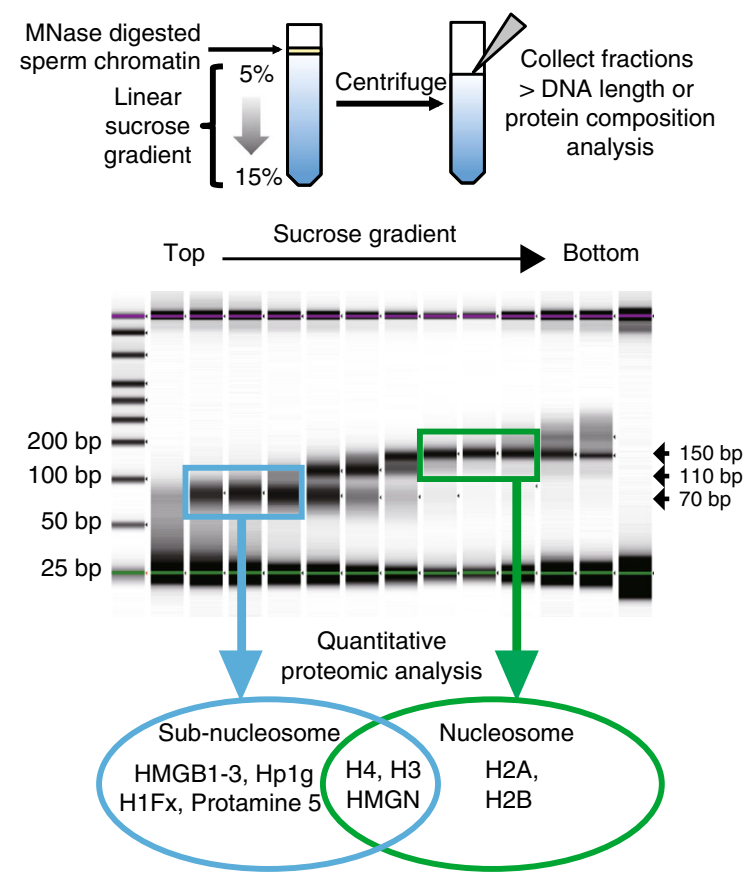

$\mathbf{f}$

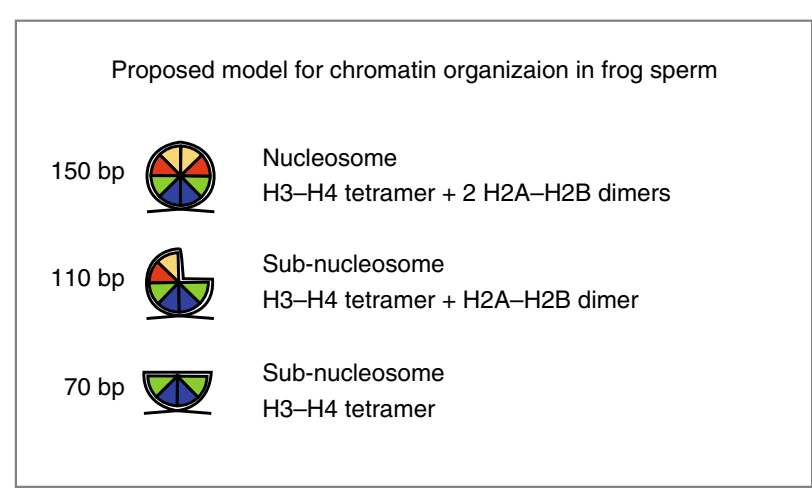

e
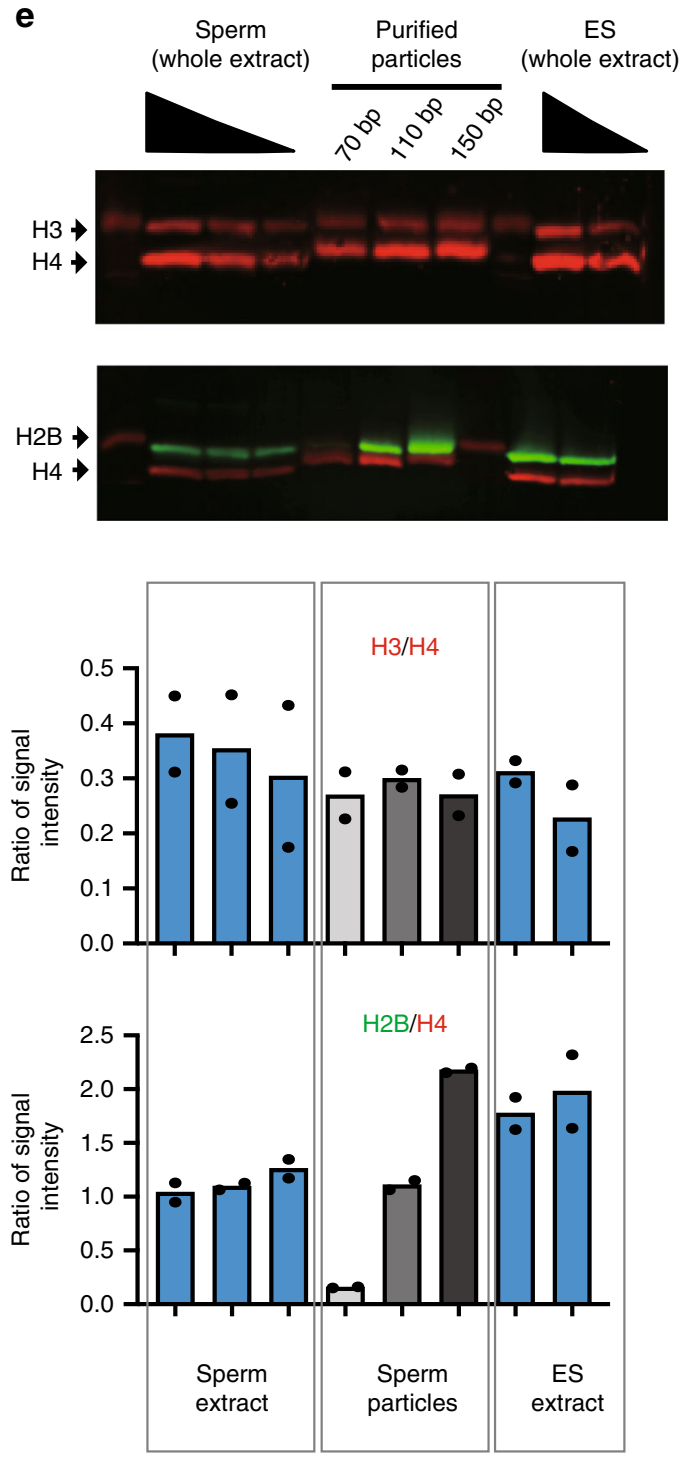

Fig. 1 Somatic level of histone $\mathbf{H 3 / H 4}$ is retained as nuclesosomes and subnucleosomes in sperm chromatin. a Xenopus laevis sperm core histones content relative to that found in a somatic cell (XL-177) as measured by quantitative WB (H2A, H2B, H3 $n=2, \mathrm{H} 4 n=3$, biologically independent samples error bar on $\mathrm{H} 4$ shows standard deviation). b DNA fragments generated by MNase digestion of Xenopus laevis sperm and somatic cell. c Schematic representation of the possible origin of subnucleosomal sized fragments generated by MNase treatment of sperm chromatin. $\mathbf{d}$ Nucleoproteic particles generated by MNase treatment of sperm are centrifugated on a sucrose gradient. Subsequently, particles isolated along the gradient are analysed for associated DNA fragment length (electrophoresis) and for associated proteins (mass spectrometry). e WB analysis confirms mass spectrometry analysis. Similar ratio of $\mathrm{H} 3$ to $\mathrm{H} 4$, and decreased level $\mathrm{H} 2 \mathrm{~B}$ to $\mathrm{H} 4$ are detected in subnucleosomes compared with nucleosomes. Xenopus sperm and mESCs are shown as control. Graphs below show the quantification of WB data $(n=2$, biologically independent samples). $\mathbf{f}$ Model of core histone composition of Xenopus laevis sperm nucleosomal and subnucleosomal particle. Source data related to $\mathbf{a}, \mathbf{b}, \mathbf{d}$ and $\mathbf{e}$ are provided as Source Data files. 
either as nucleosomes or as protamine-associated subnucleosomes. We next sought to estimate how the different histone $\mathrm{H} 3$ containing particles are distributed in the sperm genome.

Homogeneous $\mathrm{H} 3$ packaging of gene regulatory regions. To identify genomic sites where nucleosome retention or remodelling events are occurring in most sperm cells, we used MNase-seq. Indeed, because of the somatic cell-like $\mathrm{H} 3$ occupancy on the frog sperm genome, MNase-seq can be used to identify genomic sites where nucleosome retention or remodelling events are occurring in most sperm cells, an analysis that cannot be achieved in species where an extensive loss of core histone occurs ${ }^{14}$. Therefore, to reveal how the three types of $\mathrm{H} 3 / \mathrm{H} 4$-containing particles are distributed along sperm DNA, we performed paired-end sequencing of DNA fragments generated by MNase digestion of sperm chromatin $(\sim 7 \times$ genome coverage, Supplementary Fig. 2$)$. We observed that $\sim 50 \%, \sim 14 \%$ and $\sim 36 \%$ of mapped reads correspond to the 150,110 and $70 \mathrm{bp}$ length DNA fragments, respectively, in good agreement with the relative intensity observed by electrophoresis for these fragments (Figs. 1b and 2a). When taking into account the length of DNA protected by each type of particles, this indicates that the majority of the sperm genome $(66 \%)$ is protected by nucleosomes, whereas $21 \%$ and $13 \%$ is in complex with the 70 and 110 bp particles, respectively. In order to assess if spermiogenesis leads to a non-random distribution of these particles on the sperm chromatin, we applied a hidden Markov model to identify genomic regions enriched for a particular particle type (see 'Methods' for details). We observe that $\sim 72 \%$ of the genome is heterogeneous with no enrichment for any type of particle, indicating that at these genomic locations different sperm cells retain different types of particles. By contrast, the remaining $\sim 28 \%$ of the genome is homogeneous with regard to particle enrichment (Fig. 2b). Interestingly, the remodelling of nucleosomes into subnucleosomes is globally as frequent as nucleosome retention (Fig. 2a, left), but happens less heterogeneously $(19 \%(17+2)$ versus $9 \%$, Fig. 2 b). Furthermore, genomic regions showing homogeneous nucleosome retention in sperm are enriched for gene regulatory regions (promoter and enhancer), supporting a possible role for sperm-derived nucleosomes in embryonic gene regulation (Fig. 2c).

To better understand how homogeneous particle composition relates to gene regulatory regions, we performed gene clustering analysis according to the extent to which the region surrounding their TSS $+/-2 \mathrm{~kb}$ (thereafter named promoter) retains nucleosomes and/or subnucleosomes. We observe that the majority of promoters have a heterogeneous particle composition in a sperm population (Fig. 2d, cluster $6, \sim 59 \%$ of genes). However, in the remaining $41 \%$ of gene promoters, the particle composition is homogeneous in a sperm population with $\sim 7 \%$ of genes retaining nucleosomes (cluster 5) and $\sim 30 \%$ retaining subnucleosomes (cluster 2, 3 and 4). Large domain spanning most of $+/-2 \mathrm{~kb}$ intervals surrounding the TSS appear to be homogeneous for nucleosome retention (cluster 5) or remodelling (cluster 2). Interestingly, an enrichment for function related to spermatogenesis is observed for cluster 2 where the highest level of nucleosome to subnucleosome remodelling is observed (Supplementary Data 2). Here, nucleosome remodelling of spermatogenesis-related genes regulatory regions might contribute to the programming of sperm for development by resetting chromatin structure on genes transcribed during the previous developmental phase.

We conclude from these analyses that spermiogenesis is associated with homogeneous retention or remodelling of nucleosomes on gene regulatory regions in a sperm population (Fig. 2e).
H3K4 and H3K27 are always methylated on a sperm genes subset. Our results so far indicate that some sperm histone $\mathrm{H} 3$ containing particles have the required attributes to act as carrier of epigenetic information to the next generation as they are found to be retained at the same genomic location within a sperm cell population. To further characterise histone $\mathrm{H} 3$-containing particles in sperm chromatin, we investigated H3 trimethylation on lysine 4 and lysine 27, two well-studied modifications associated with an active and repressed state of gene expression, respectively. We used internal standard calibrated chromatin immunoprecipitation sequencing (ICeChIP-seq ${ }^{18}$ ) to estimate the percentage of histone $\mathrm{H} 3$ methylation at a given locus in a sperm population (apparent histone methylation density, HMD) (Supplementary Fig. 3 and 'Methods'). We observed that most of the genomic loci with methylated histones have low levels of methylation (Fig. 3a, $0 \%<\mathrm{HMD}<80 \%)$. At these genomic sites histone methylation is therefore heterogeneous within the sperm population. However, $\sim 0.4 \%$ and $6 \%$ of the sperm genome show an HMD $>80 \%$ for $\mathrm{H} 3 \mathrm{~K} 4$ and $\mathrm{H} 3 \mathrm{~K} 27$, respectively. These sites have histone methylation in most sperm and cover a fraction of the genome similar to that found in an ESC population ${ }^{18}$, suggesting that modified histones might have functional relevance in sperm as is the case for ESC (Fig. 3a). When focusing on peaks of histone marks, we observed that $20 \%$ and $70 \%$ of peaks have an HMD $>80 \%$ for $\mathrm{H} 3 \mathrm{~K} 4$ and H3K27, respectively (Fig. 3b). Given the high level of retained histone $\mathrm{H} 3$ in Xenopus sperm chromatin (Fig. 1a), we conclude that, at these genomic sites, most sperm harbour a methylated H3. Such genomic sites are enriched for gene regulatory regions (TSSs and enhancers (Fig. 3c)), and appear enriched for binding motifs recognised by transcription factors implicated in early embryonic development (i.e., NFY-A/Dux ${ }^{23}$; Ascl1 ${ }^{24}$, ZFP28125; Fig. 3d). High methylation density for H3K4 is localised in the immediate vicinity of the TSSs whereas high level of $\mathrm{H} 3 \mathrm{~K} 27$ methylation is observed on most of the $+/-2 \mathrm{~kb}$ interval surrounding the TSSs (Fig. 3e). Several gene clusters show co-occurrence of high degree of methylation density for both $\mathrm{H} 3 \mathrm{~K} 4$ and $\mathrm{H} 3 \mathrm{~K} 27$ (clusters 2, 4 and 5) and are associated with GO categories related to development, especially when H3K4 methylation cover a broader domain around the TSS (cluster 4) (Supplementary Data 3).

To conclude, specific regulatory regions near developmental genes are homogeneously methylated on H3K4 and/or H3K27 in most sperm of a population.

Homogeneous bivalent $\mathrm{H} 3$ marking on sperm developmental genes. So far, we have identified parts of the sperm genome that are homogeneous in the way histone $\mathrm{H} 3$ package chromatin (as nucleosomes or subnucleosomes, Fig. 2) and those that are homogeneous for the methylation of histone $\mathrm{H} 3$ (on Lys4 or Lys27, Fig. 3). We next investigated if homogeneity for these two types of histone $\mathrm{H} 3$ epigenetic features occurs at the same genomic location.

We first ask if the chromatin sites with homogeneous histone methylations (peaks of $\mathrm{H} 3 \mathrm{~K} 4$ or $\mathrm{H} 3 \mathrm{~K} 27$ with $\mathrm{HMD}>80$ ) are occurring at locations that always retain $\mathrm{H} 3$ within a nucleosome, always remodel $\mathrm{H} 3$ into subnucleosomes or have either of these particles in a sperm population (Fig. 4a, b). Interestingly, we observe an enrichment for homogeneous histone $\mathrm{H} 3$ methylation at the genomic locations where nucleosomes are always retained, and to a lesser extend at genomic locations where nucleosomes are always remodelled into subnucleosomes. In particular there is a tendency, albeit weak, for homogeneous retention of $\mathrm{H} 3 \mathrm{~K} 4 \mathrm{me} 3$ in the context of a nucleosome.

As they could represent instructions for future embryonic gene expression we further characterised chromatin sites homogeneous 
a

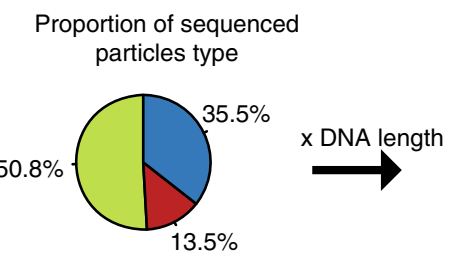

Proportion of sequenced genome by particle types

b

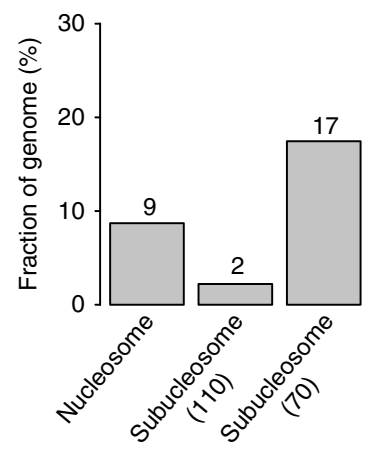

C

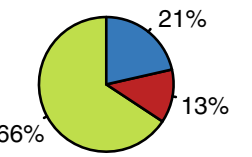

Nucleosome (150 bp)

Subnucleosome (110 bp)

Subnucleosome (70 bp)
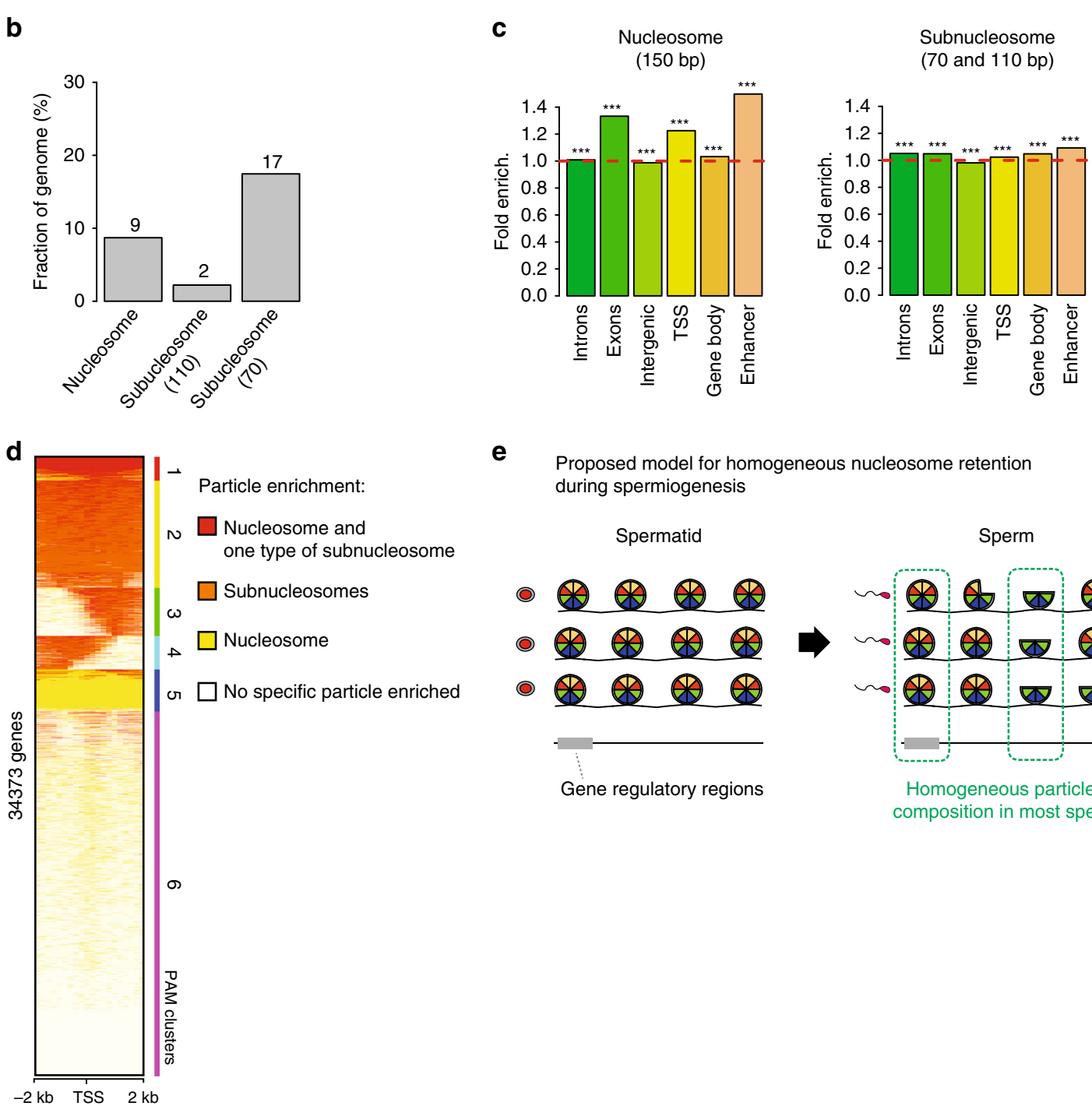

e

Proposed model for homogeneous nucleosome retention during spermiogenesis

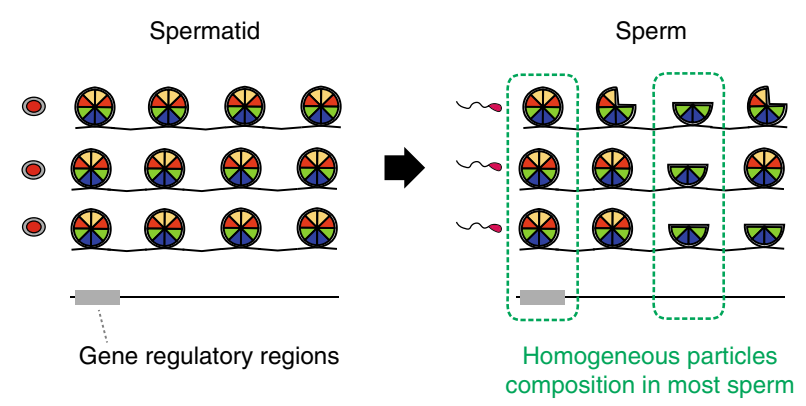

Homogeneous particles

Fig. 2 Nucleosome loss/retention associated with spermiogenesis occurs non-randomly in a large fraction of the genome. a Relative abundance (left) and genome coverage (right) of nucleosomes and subnucleosomes in the sperm chromatin. The left pie chart reports the fraction of DNA fragments from Xenopus Laevis sperm corresponding to each type of particle; the right pie chart reports the fraction of genome covered by each type of particle. $\mathbf{b}$ Fraction of the genome with homogeneous particles composition. The bar graph indicates the percentage of the genome that possess nucleosomal or subnucleosomal structure across most sperm of the population sequenced (genome binned in 50 bp windows). c Fold enrichment (observed/random) over 1000 randomisations for homogeneous nucleosomes (left) or subnucleosomes (right) composition at the indicated genomic features; ${ }^{\star \star \star}$ : empirical $p$ value $<1 \mathrm{e}-3$. Input data from two independent replicates were pooled. d PAM (partitioning around medoids) clustering of promoter (TSS $+/-2 \mathrm{~kb}$ ) according to enrichment for nucleosomes or subnucleosomes. e Model of nucleosomes and subnucleosomes distribution in sperm and spermatid. Source data related to $\mathbf{a}, \mathbf{b}$ and $\mathbf{d}$ are provided as Source Data files.

for $\mathrm{H} 3$ particle type and for $\mathrm{H} 3$ methylation, focusing on gene regulatory regions (Fig. $4 \mathrm{c}$ and Supplementary Data 4). To that end, we clustered all gene TSSs according to homogeneity for the four $\mathrm{H} 3$ epigenetic parameters evaluated in this study (methylation of $\mathrm{H} 3 \mathrm{~K} 4$, methylation of $\mathrm{H} 3 \mathrm{~K} 27$, nucleosome retention and nucleosome remodelling). The $+/-2 \mathrm{~kb}$ region around the TSS is divided in $200 \mathrm{bp}$ bins. For each bin, the four epigenetic parameters are classified as either homogeneous or heterogeneous. Specifically, histone methylation is considered homogeneous if the bin has an $\mathrm{HMD}>80 \%$, and heterogeneous otherwise. In addition, a bin is classified as homogeneous for the presence of a nucleosome or for subnucleosome if an enrichment is detected (two-layered inference strategy, see $\mathrm{M} \& \mathrm{M})$ and heterogeneous otherwise. In that way we obtain a 
a

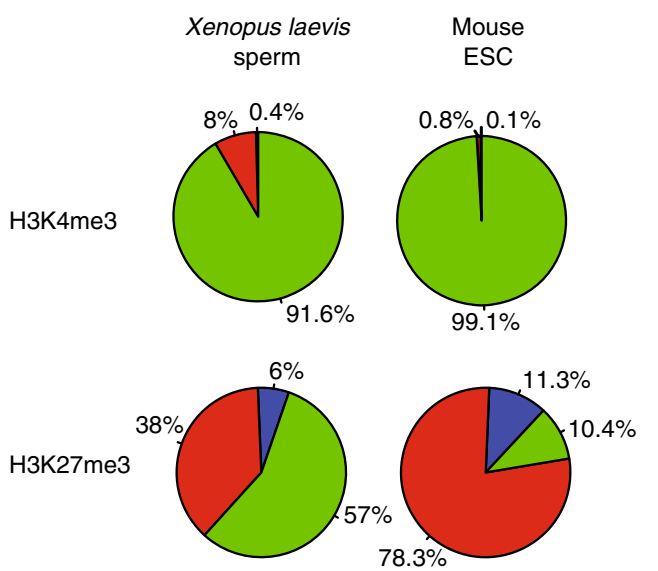

$\mathrm{HMD}>80 \%$

$20 \%<\mathrm{HMD}<80 \%$

HMD $<20 \%$ b
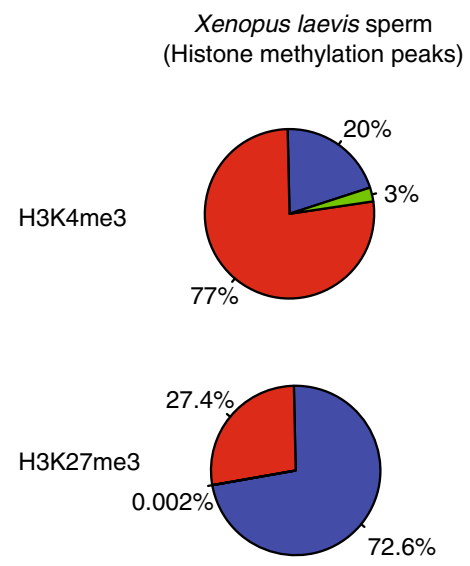

$\mathrm{HMD}>80 \%$

$20 \%<\mathrm{HMD}<80 \%$

HMD $<20 \%$
C
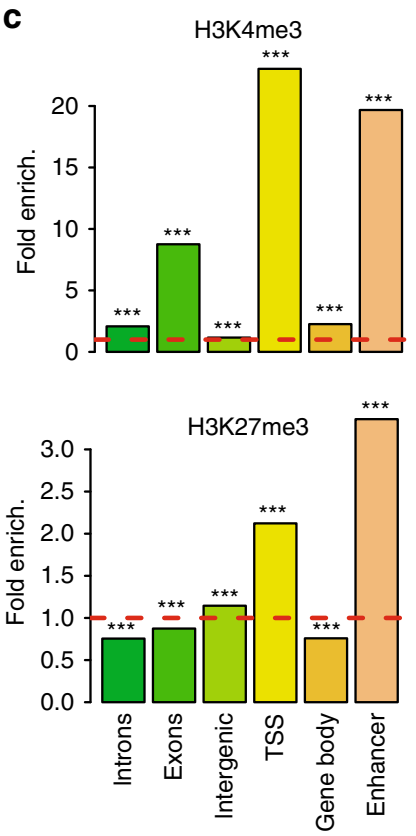

d

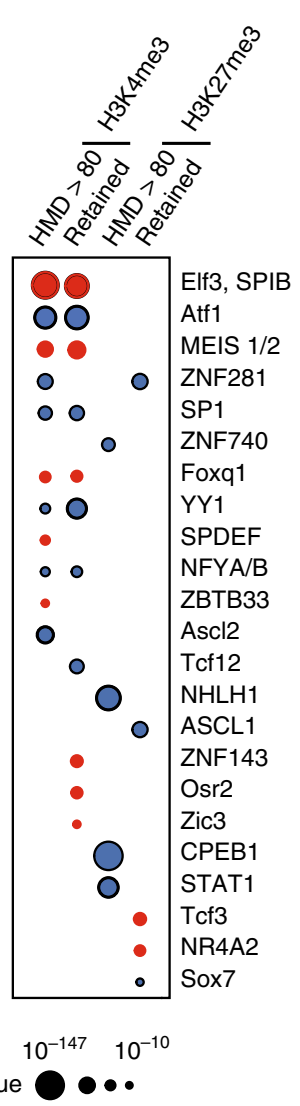

e

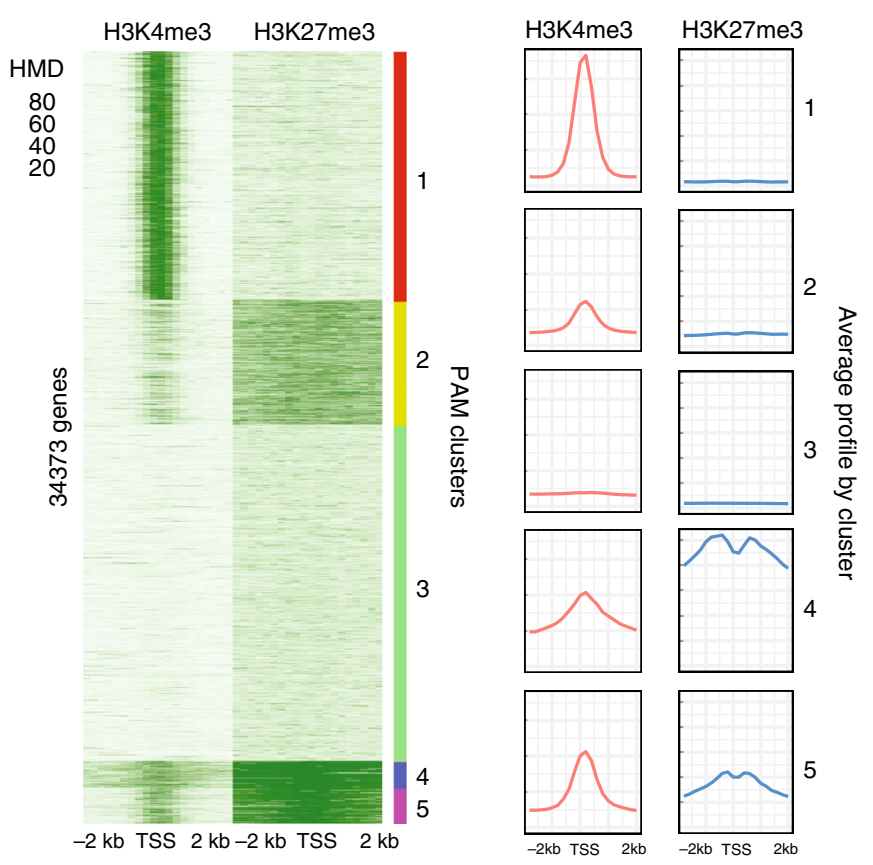

Fig. 3 A fraction of the genome harbours methylated H3K4 and/or H3K27 at the same location in most sperm of a population. a Percentage of the genome with different range of apparent histone H3 methylation density (HMD) on Lysine 4 and 27 in Xenopus Laevis sperm and mouse ESC. b Percentage of H3K4me3 and H3K27me3 peaks with different range of HMD in Xenopus Laevis sperm. c Fold enrichment (observed/random) over 1000 randomisations of peaks with homogeneous histone methylation (HMD $>80)$ at the indicated genomic features; ${ }^{\star \star \star}$ : empirical $p$ value $<1 \mathrm{e}-3$. ICe-ChIP data from two independent replicates were pooled. $\mathbf{d}$ Dot matrix showing transcription factors with enriched motifs ( $y$-axis) in the different histone methylation categories ( $x$-axis). Circle size represents $-\log 10$ ( $p$ value) of the motif enrichment; and the circle colour indicates whether evidences exist indicating that the corresponding transcription factors is present maternally (blue) or not (red). Retained HMD $>80$ peaks correspond to sperm histone methylation peaks maintained after extract treatment as in Fig. 5. e Heat map after PAM clustering of promoters (TSS $+/-2 \mathrm{~kb}$ ) according to histone H3-methylation density on Lysine 4 and 27. The plots on the left show the average HMD profile for each cluster. Source data related to $\mathbf{a}, \mathbf{b}, \mathbf{d}$, and $\mathbf{e}$ are provided as Source Data files. 

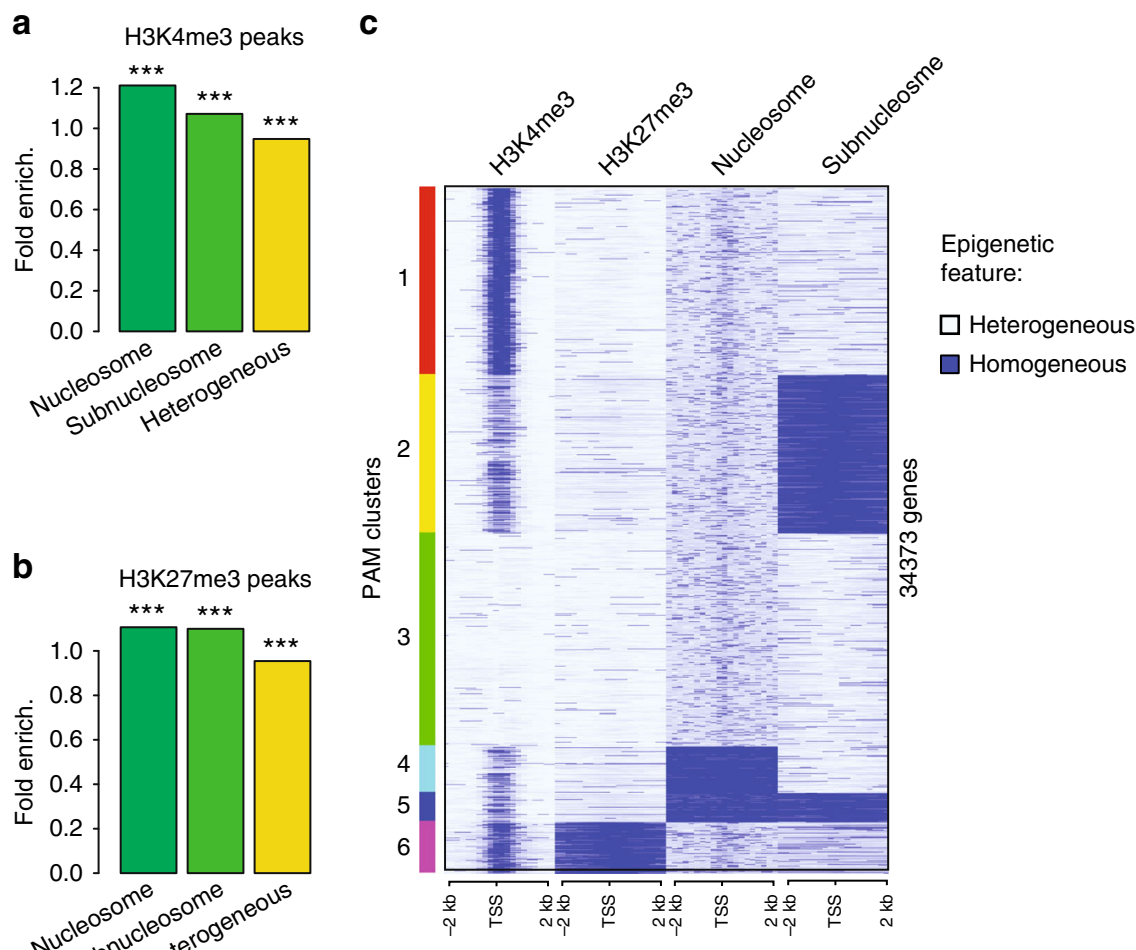

Fig. 4 Homogeneous bivalent marking of histone $\mathbf{H 3}$ on sperm developmental genes. a Fold enrichment (observed/random) over 1000 randomisations of peaks with homogeneous H3K4 methylation $(\mathrm{HMD}>80$ ) in regions homogeneous for nucleosomes, homogeneous for subnucleosomes or with heterogeneous particle composition in a sperm population; ${ }^{\star \star \star}$ : empirical $p$ value $<1 \mathrm{e}-3$. b Same as in a for H3K27 methylation. c PAM clustering of promoter (TSS +/ $-2 \mathrm{~kb}$ ) according to homogeneity for methylation of histone H3 (HMD > 80) on Lysine 4, on Lysine 27, enrichment for nucleosomes and enrichment for subnucleosomes. Source data related to $\mathbf{c}$ is provided as a Source Data file. ICe-ChIP data from two independent replicates were pooled.

view of the sperm epigenetic landscape at TSS that reveals features conserved within the sperm population.

As expected, homogeneous $\mathrm{H} 3 \mathrm{~K} 4 \mathrm{me} 3$ is mostly found in the vicinity of the TSSs where homogeneous nucleosome retention is also observed. However, this analysis also revealed that, as a whole, TSSs with the less heterogeneous histone methylation (H3K4me3 cluster 1, and H3K27me3 cluster 6) differ from TSSs characterised by homogenous block of nucleosome and/or subnucleosome (clusters 2, 4 and 5). In particular, genes with stretch of homogeneous nucleosome retention (cluster 4) or remodelling (cluster 2) surrounding the TSS are associated with reduced H3K4me3 density when compared with genes with heterogeneous particles composition (clusters 1 and 6). We also identified a set of genes with homogeneous methylation on both H3K27me3 and H3K4me3 (cluster 6). This set of genes show cooccurrence of K4 and K27 methylation in most sperm. These bivalent genes include many transcription factors involved in early embryogenesis (i.e., members of the Hox, Fox, Sox, Gata, Tbx and Pax transcription factor families). Moreover, globally, these bivalent genes are associated with GO terms related to development (Supplementary Data 4).

We conclude that, in general, homogeneity for histone methylation and histone particle composition is occurring on different group of genes. Importantly, this analysis reveals the existence of bivalent genes marking of developmental genes in all sperm.

Sperm-methylated histones are maintained during DNA replication. Because the epigenetic features investigated in this study are present at the same genomic location in most sperm cells, they could represent necessary information delivered by the sperm at fertilisation to support embryonic development. Such necessary epigenetic cues would need to be transmitted to the cells of the developing embryo to exert their action. To test this hypothesis, we first incubated permeabilised sperm in egg extract to mimic the chromatin assembly and replication steps associated with the first embryonic cycle ${ }^{26}$ (Fig. 5a and Supplementary Fig. 4). H3K4me3 and H3K27me3 ChIP-seq analysis indicated that $75 \%$ of sperm $\mathrm{H} 3 \mathrm{~K} 4 \mathrm{me} 3$ peaks and $24 \%$ of $\mathrm{H} 3 \mathrm{~K} 27 \mathrm{me} 3$ peaks are retained after egg extract treatment (Fig. 5b). In sperm, prior to treatment, these retained peaks had higher methylation density (i.e., less heterogeneous in the sperm population) and were larger in size than lost peaks (Fig. 5c, d). We also observed that retention of peaks is favoured over gene regulatory regions (Fig. 5e). However, the context within which high histone $\mathrm{H} 3$ methylation occurs (with or without enrichment for a given $\mathrm{H} 3$ particle) is not generally predictive of the fate of the methylated histone post replication (Supplementary Fig. 5). Finally, sperm incubation with extracts containing the DNA replication inhibitor gemi$\operatorname{nin}^{27,28}$ suggests that most histone methylation peak loss following treatment is associated with chromatin assembly on sperm DNA rather than with DNA replication (Supplementary Fig. 6).

Focusing on the embryonically abundant H3K4me3, we evaluated the fate of sperm-methylated histones in vivo after several replication cycles. For that purpose, we performed ChIPseq analysis using formaldehyde-fixed early blastula embryos (after $\sim 8$ embryonic cell cycles but before the activation of zygotic transcription) (Fig. 5a). We observed that almost all H3K4me3 peaks detected in blastulae were already present in the sperm chromatin (Fig. 5f). Similar to peak retention after egg extract treatment, we observed that $\mathrm{H} 3 \mathrm{~K} 4 \mathrm{me} 3$ peaks retained in blastula 
a

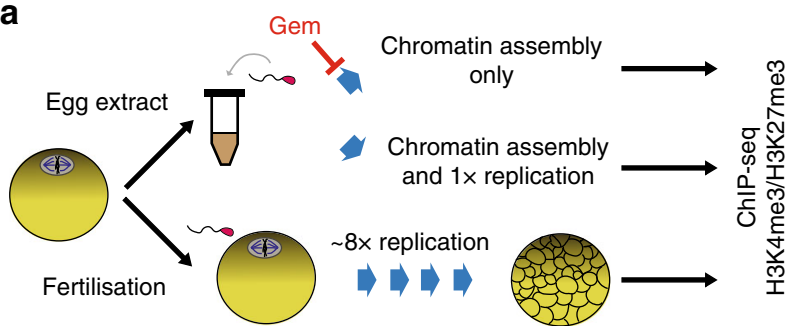

b

H3K4me3 peaks

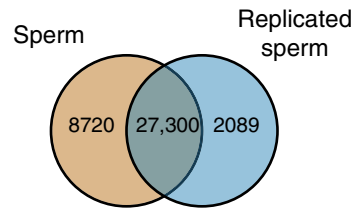

C

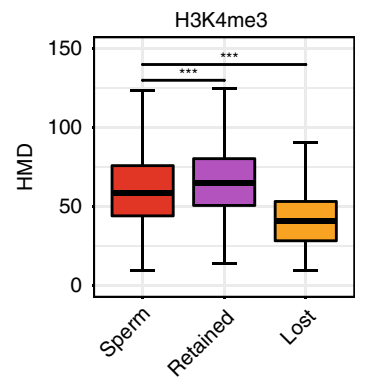

d

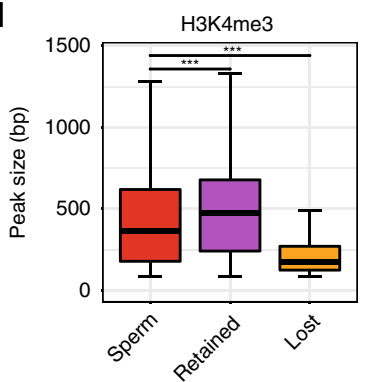

e

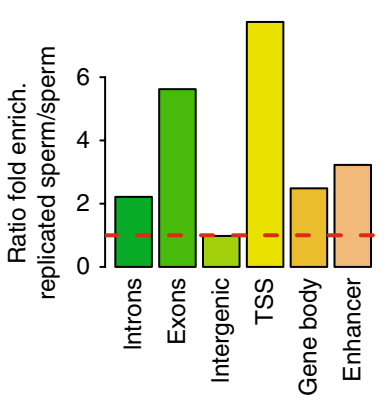

H3K27me3 peaks
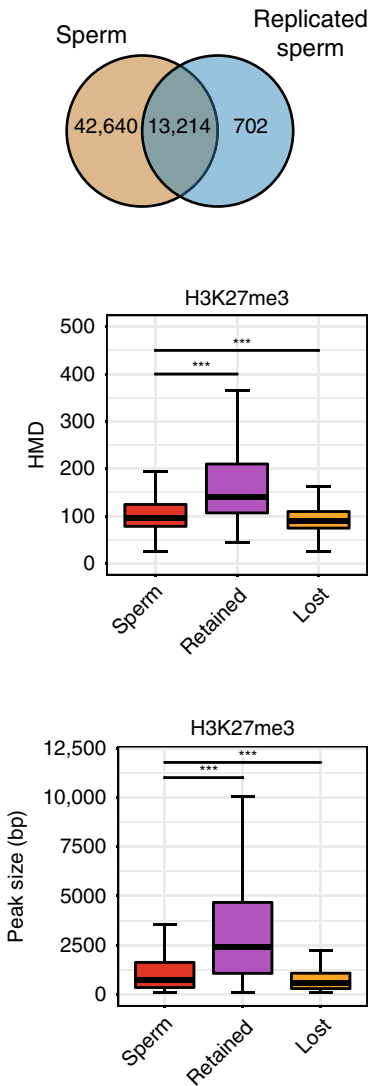

H3K27me3

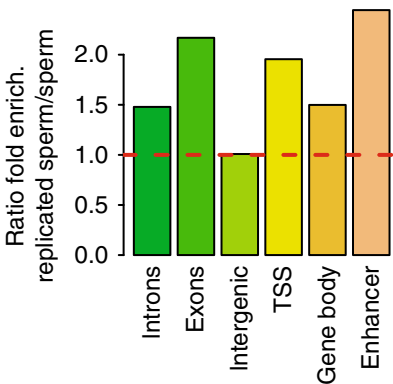

f

H3K4me3 peaks

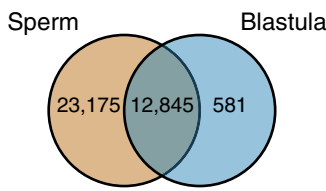

g

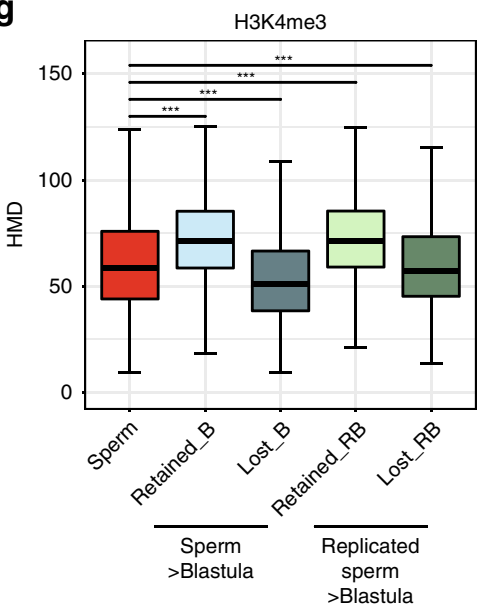

h

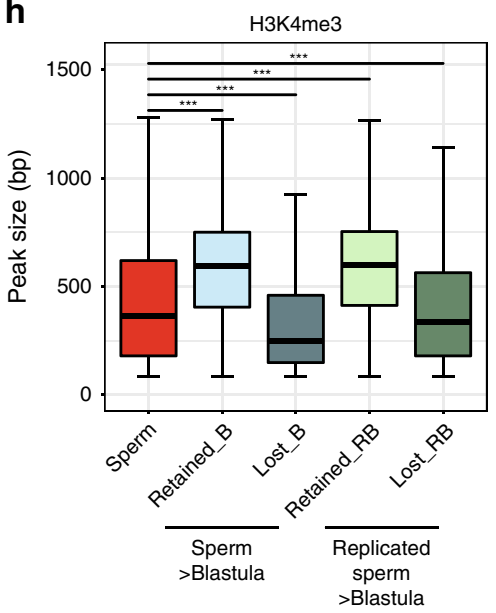

i embryos corresponds to gene regulatory sites that harbour stretches of H3K4me3 in most sperm cells (Fig. 5g-i).

These observations show that the epigenetic information present at the same genomic location in most sperm cells can be faithfully transmitted to the mitotic progeny in early frog embryos.
Sperm-methylated histone programmes embryonic gene expression. We then thought to evaluate if the homogeneous epigenetic fraction of the sperm genome that is transmitted to the embryo contributes to the regulation of embryonic gene expression. We first compared early embryonic expression of genes with heterogenous methylation in sperm to that of genes that have a 
Fig. 5 Homogeneously methylated sperm histones are maintained during early embryonic replication. a Experimental setup to monitor the fate of sperm-methylated histone peaks after replication. b Overlap between peaks of H3K4me3 and H3K27me3 before and after replication of sperm chromatin in egg extract. c Boxplots of HMD for all sperm peaks and for peaks that are lost or retained after replication. $\mathbf{d}$ Boxplots of the size of all sperm peaks, and of peaks that are lost or retained after replication. Data in c and $\mathbf{d}$ are obtained from N. sperm peaks H3K4me3: 36020; N. sperm retained H3K4me3: 27300; N sperm lost H3K4me3: 8715. N. sperm peaks H3K27me3: 55854; N. sperm retained H3K27me3: 13214; N sperm lost H3K27me3: 42635.

${ }^{* \star *} p$ value $<1$ e-3 (two-sample Kolmogorov-Smirnov test). e Ratio of fold enrichment of peaks retained after replication over those lost after replication at indicated genomic features. Fold enrichments (observed/random) were obtained from 1000 randomisations and all instances showed an empirical $p$ value $<1 \mathrm{e}-3$. f Overlap between peaks of H3K4me3 in sperm and in blastula embryos. $\mathbf{g}$ Boxplots indicating HMD for all sperm peaks and for peaks that are lost or retained in blastula compared with sperm, and lost or retained in blastula compared with replicated sperm. $\mathbf{h}$ Boxplots of peak sizes for all sperm peaks and for peaks lost and retained in blastula compared with sperm, and in blastula compared with replicated sperm. In $\mathbf{g}$ and $\mathbf{h}{ }^{\star \star \star} p$ value $<1 \mathrm{e}-3$ and are obtained by the two-sample Kolmogorov-Smirnov test. $\mathbf{i}$ Ratio of fold enrichment of peaks retained in blastula versus those in sperm at indicated genomic features. This ratio has been obtained as in e. HMD is from data pooled from two independent replicates. Peaks retention/lost are consensus from three independent replicates.

homogeneous methylation in sperm and that retain this methylation after replication (Supplementary Data 5). We find that the set of genes associated with homogenous methylation in sperm is enriched for genes expressed at zygotic gene activation (ZGA) (Fig. 6a). Specifically, homogeneous methylation of H3K27 in sperm is associated with ZGA genes involved in development whereas homogeneous methylation of $\mathrm{H} 3 \mathrm{~K} 4$ in sperm is associated with ZGA genes involved in housekeeping function. Importantly, genes with heterogeneous methylation in the sperm population do not show such enrichment for these ZGA gene categories. Therefore, the epigenetically homogeneous fraction of the sperm genome that is maintained after replication is strongly associated with early embryonic gene transcription.

To further test the idea that homogeneous marking in sperm is functionally linked to embryonic gene expression, we asked whether interference with $\mathrm{H} 3 \mathrm{~K} 4$ or $\mathrm{H} 3 \mathrm{~K} 27$ methylation at fertilisation, as reported in our previous work $^{2}$, preferentially affect genes with an homogeneous methylation in a sperm population. In that study we identified genes that were misregulated in gastrulae generated from egg expressing a demethylase targeting either H3K4 (Kdm5b) or H3K27 (Kdm6b) methylation prior to sperm injection. The set of genes that are misregulated upon demethylation of H3K27me3 (Kdm6b sensitive) is enriched for genes with homogeneous methylation of H3K27me3 in sperm (Fig. 6b). In addition, a significant proportion of genes sensitive to both demethylation of H3K27 and depletion for the maternally provided factor Ascll harbour homogeneously methylated H3K27 and the binding motif for this transcription factor (Supplementary Fig. 7). This suggests that sperm-provided modified histones might regulate maternal factor activity.

Unexpectedly, however, we observe that the set of genes misregulated upon $\mathrm{H} 3 \mathrm{~K} 4 \mathrm{me} 3$ demethylation ( $\mathrm{Kdm} 5 \mathrm{~b}$ sensitive) is also enriched for gene with homogeneous methylation of H3K27me3 (Fig. 6b). This could be explained if demethylation of sperm $\mathrm{H} 3 \mathrm{~K} 4 \mathrm{me} 3$ affects subsequent embryonic gene expression only when it co-occurs with methylation of H3K27 (i.e., sperm bivalent genes). To test this hypothesis we first investigated the fate of the fraction of sperm genome homogeneously methylated on $\mathrm{H} 3 \mathrm{~K} 4 \mathrm{me} 3$ only, $\mathrm{H} 3 \mathrm{~K} 27 \mathrm{me} 3$ only or both residues (bivalent) (Fig. 6c). We find that peaks of homogeneous $\mathrm{H} 3 \mathrm{~K} 4 \mathrm{me} 3$ in sperm are very well conserved after replication $(>80 \%)$ whereas peaks of homogeneous $\mathrm{H} 3 \mathrm{~K} 27 \mathrm{me} 3$ are poorly retained $(<25 \%)$. Interestingly when co-occuring with $\mathrm{H} 3 \mathrm{~K} 4 \mathrm{me} 3$, H3K27me3 peaks are better retained after replication $(\sim 50 \%)$. When focusing on the set of genes associated with these retained bivalent peaks, we observed an enrichment for genes misregulated upon $\mathrm{H} 3 \mathrm{~K} 4$ or $\mathrm{H} 3 \mathrm{~K} 27$ methylation (Fig. 6d).

We conclude that the homogenous fraction of sperm-modified histone that is propagated in early embryos prime developmental genes for embryonic expression. We next sought to evaluate if such epigenetic regulatory principle apply in human.

Homogeneous histone methylation in a human sperm population. We first applied ICe-ChIP to quantify the level of methylation of the fraction of histone $\mathrm{H} 3$ retained in mature human sperm. To that end human sperm from a fertile individual were treated with an MNase concentration that yields nucleosome-sized fragments as well as smaller fragments (Supplementary Fig. 8). Digested chromatin was used for H3K4me3 and $\mathrm{H} 3 \mathrm{~K} 27 \mathrm{me} 3 \mathrm{ICe}-\mathrm{ChIP}-\mathrm{Seq}$ analysis. Interestingly, in human, $\mathrm{H} 3 \mathrm{~K} 4 \mathrm{me} 3$ and H3K27me3 ChIP recovers only nucleosome-sized fragment (Supplementary Fig. 8). So unlike in Xenopus, in human-sperm-modified histone $\mathrm{H} 3$ are not found associated with small DNA fragments generated by MNase digestion. We observed that part of the human sperm genome harbours a high density of $\mathrm{H} 3 \mathrm{~K} 4 \mathrm{me} 3$ or $\mathrm{H} 3 \mathrm{~K} 27 \mathrm{me} 3$, albeit to a lower extent than observed in Xenopus and in accordance with the lower histone retention in human sperm (Fig. $7 \mathrm{a}$, left). Clustering promoters according to $\mathrm{H} 3 \mathrm{~K} 4 \mathrm{me} 3$ and $\mathrm{H} 3 \mathrm{~K} 27 \mathrm{me} 3$ density highlighted further differences between human and Xenopus (Fig. $7 \mathrm{~b}$ and Supplementary Data 6). In human, H3K4me3 density is not particularly higher at the TSSs as observed in frog (compare Figs. 3 e and $7 \mathrm{~b}$ ). Instead high H3K4me3 HMD is found on broad domains around TSSs of a limited number of genes (cluster 4 , 1570 genes). This suggests that human spermiogenesis is associated with a removal of the majority of $\mathrm{H} 3 \mathrm{~K} 4 \mathrm{me} 3$ that is usually associated with a large proportion of genes TSSs in somatic cells.

To focus on the fraction of the human sperm genome that is homogeneously methylated on histone $\mathrm{H3}$, we then identified peaks of histone modifications and computed their HMD. Overall, the peaks identified are well conserved between our study and previous work $^{5}$ indicating that peak calling is consistent across a range of MNase treatments (Supplementary Data 7). Interestingly, however, our analysis shows that in human, a very large fraction of histone methylation peaks identified by conventional ChIP-seq corresponds to low HMD and are therefore heterogeneous in a sperm population (Fig. 7a, right). Nonetheless, some human sperm genes have peaks of high density of histone H3K4me3 (130 genes) or H3K27me3 (320 genes) around their TSSs (i.e., BMI, TBX3, Fig. 7c and Supplementary Data 8). Genes associated with peaks of $\mathrm{H} 3 \mathrm{~K} 4 \mathrm{me} 3$ or $\mathrm{H} 3 \mathrm{~K} 27 \mathrm{me} 3$ methylation in sperm, irrespective of HMD level, show a significant overlap between human and Xenopus and these gene sets are enriched for genes expressed at ZGA in both species (Fig. $7 \mathrm{~d})^{29}$. By contrast, no conservation is observed between Xenopus and human orthologous genes associated with the homogeneous-methylated fractions (peaks with HMD > 80) of the sperm genome (Fig. 7d). However, in both species the set of genes with high $\mathrm{H} 3 \mathrm{~K} 27 \mathrm{me} 3 \mathrm{HMD}$ is related to 


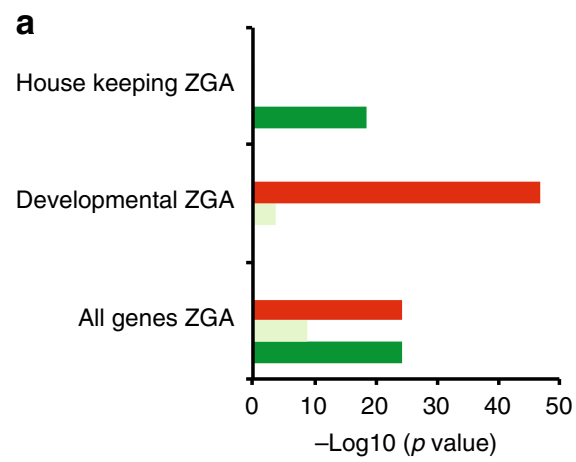

b

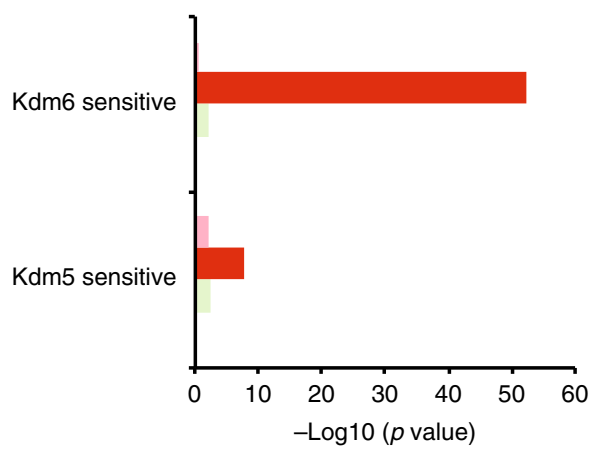

K27 heterogeneous

- K27 homogeneous \& retained

K4 heterogeneous

- K4 homogeneous \& retained

c

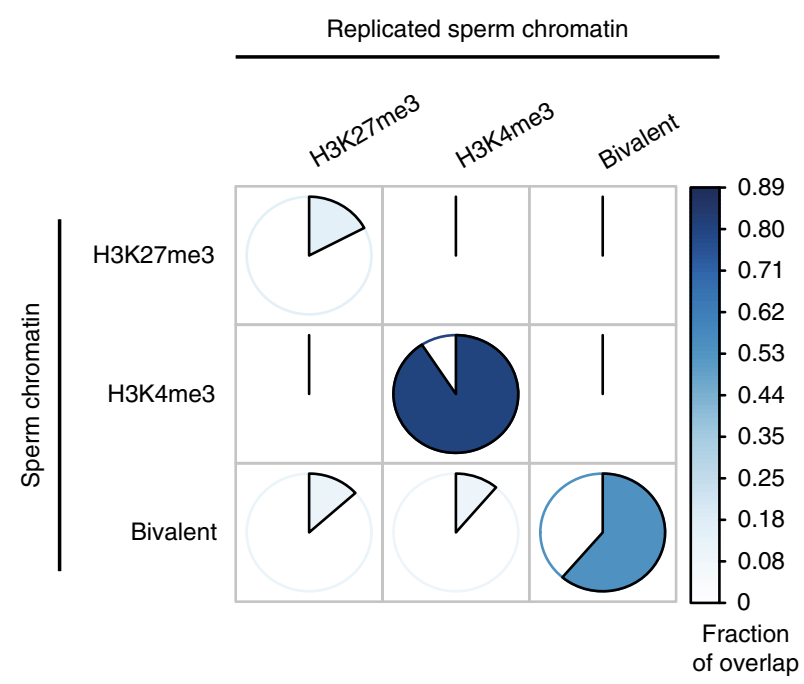

d

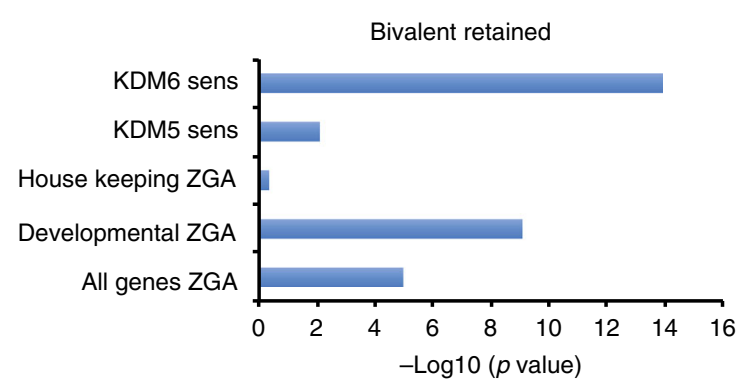

developmental functions (Supplementary Tables 3 and 7). In addition, an enrichment of high HMD peaks for ZFP281 binding sites, a transcription factor implicated in early mammalian embryonic development, is found in both human and Xenopus. These observations raise the possibility that the fraction of the sperm genome with homogenous histone methylation could contribute to early embryonic development in human as it is the
K27 heterogeneous

- K27 homogeneous \& retained

K4 heterogeneous

- K4 homogeneous \& retained 
Fig. 6 The homogeneously methylated histone fraction in frog sperm chromatin regulates embryonic gene expression. a Barplot of enrichment $p$ values (-log10) in set of genes expressed at zygotic gene activation (all-, developmental- and house keeping-ZGA genes) for the presence of different type of $\mathrm{H} 3 \mathrm{~K} 4 \mathrm{me} 3$ or H3K27me3 sperm peaks. pink and light green bars = enrichment $p$ value for heterogenous $(\mathrm{HMD}<80)$ peaks in promoter; red and green bars $=$ enrichment $p$ value for homogeneous $(H M D>80)$ peaks in promoter that are also retained after replication. $P$ values determined by the $\chi^{2}$ proportion test evaluating if the proportion of gene of interest is higher (alternative = 'greater') than the genome-wide proportion (i.e., expected proportion). $\mathbf{b}$ Barplot of enrichment $p$ values $(-\log 10)$ in set of genes whose embryonic expression is sensitive to the presence of histone H3K4 demethylase $(\mathrm{Kdm} 5 \mathrm{~b})$ or histone $\mathrm{H} 3 \mathrm{~K} 27$ demethylase $(\mathrm{Kdm} 6 \mathrm{~b})$ at fertilisation ${ }^{2}$ for the presence of the aforementioned sperm peaks categories. $P$ values are obtained as in a. c Pie chart indicating the percentage of the homogeneously methylated histone present in sperm that are retained after egg extractmediated replication. Three type of sperm peaks are considered: homogeneous for H3K27me3 only, homogeneous for H3K4me3 only and homogeneous for H3K27me3 and H3K4me3 (bivalent). The area of the coloured sector (together with the colour) indicates the fraction of the overlap between each pairwise comparison. $\mathbf{d}$ Barplot of enrichment $p$ values $(-\log 10)$ in various set of genes for the presence of a homogeneous bivalent $\mathrm{H} 3 \mathrm{~K} 4 \mathrm{me} 3$ and $\mathrm{H} 3 \mathrm{~K} 27 \mathrm{me} 3$ retained after replication. $P$ values are obtained as in $\mathbf{a}$. HMD are from data pooled from two independent replicates. Peaks retention/lost are consensus from three independent replicates. Set of $\mathrm{kdm} 5$ and $\mathrm{kdm} 6$ sensistivite genes are from three independent replicates.

exclusive on chromatin ${ }^{30}$. Therefore, we would expect that if peaks of high HMD methylation on H3K27 reflected the situation in most sperm cells, they would be associated with genomic regions that are uniformly DNA hypomethylated in a human sperm population. We checked this proposition using published bisulfite sequencing data from single human sperm cells ${ }^{31}$. This dataset allowed us to identify genomic region that harbour unmethylated DNA in all sperm. We found that high HMD peaks $(\mathrm{HMD}>80)$ are indeed more likely to be associated with such unmethylated sperm DNA than low HMD peaks $(0<\mathrm{HMD}<80)$ (Fig. 7e). The observed correlation between lack of DNA methylation in all sperm and high HMD peak of H3K27 fit with the hypothesis that high HMD peaks represent methylated histones present in most human sperm cells. In addition, the set of genes with high HMD on H3K27 in sperm is enriched for genes that have a closed TSS configuration in most cells of the human embryos undergoing ZGA, as shown by ATACseq $^{31}$ (Fig. $7 \mathrm{f}$ ). This suggests that methylated histones on sperm gene TSSs could regulate chromatin accessibility in embryos at ZGA.

We conclude that in human sperm, histones near some developmental genes are always retained in their methylated form. We provide indirect evidence that methylated histones might also be homogeneously distributed in a human sperm population as in Xenopus and could contribute to the regulation of embryonic chromatin status at ZGA.

\section{Discussion}

Multiple lines of evidence point towards the transmission of epigenetic information from parents to offspring ${ }^{32}$. However, the molecular basis of this epigenetic information is unclear. In particular the notion that sperm-derived histones are randomly retained along the genome has gained support, leading to the proposal that modified histones cannot be the basis for the epigenetic information required for embryo development ${ }^{14}$. Here we provide evidence to the contrary. The particular core histone remodelling event occurring during Xenopus laevis spermiogenesis enabled us to refine epigenetic maps of the sperm by identifying genomic sites where most sperm of a population harbours a given epigenetic feature. This approach uncovers a subset of genes in the genome that retains modified histones in all sperm (Fig. 7g). Compared with genes with heterogeneous epigenetic composition, these genes are characterised by their expression at ZGA, their persistent association with modified histones after replication and their sensitivity to histone demethylation at fertilisation. Our analysis demonstrates that sperm homogenously modified histones across a cell population contribute to the transmission of epigenetic information necessary for the regulation of embryonic gene expression in Xenopus laevis. Moreover, we identify genomic sites where histones are always retained as methylated in human sperm. Although we cannot assume that all sperm retain histones at these locations in human, these genomic sites represent potential candidate regions for the epigenetic programming of human sperm for embryonic expression. This suggests that a modified histone-based mechanism of intergenerational epigenetic transmission might be conserved between species.

How is the epigenetic information encoded in sperm-modified histone then transmitted in the developing embryos? In Zebrafish and Xenopus, 10-12 cell division occur before the major wave of zygotic genome activation. In order to affect embryonic gene expression, sperm-derived epigenetic information therefore needs to be maintained through multiple cell division. In Zebrafish, previous work indicated that modified histones were not detected at early embryonic stage, ruling out direct transmission of spermderived modified histones during early embryogenesis ${ }^{33,34}$. However more recent work indicated that sperm-derived histone variant H2A.Z acts as a placeholder in early embryos where it regulates DNA methylation required for proper transcription and development ${ }^{35}$. In the case of Xenopus laevis sperm a direct transmission mechanism of $\mathrm{H} 3 \mathrm{~K} 27 \mathrm{me} 3$ is also unlikely. Indeed, we observe that a much larger fraction of $\mathrm{H} 3 \mathrm{~K} 27$ methylation than that of H3K4 methylation is lost after replication (Fig. 5b), in agreement with H3K27me3 ChIP-seq data obtained in Xenopus tropicalis that detected very low level of this mark in gastrulae ${ }^{36}$. We hypothetize that a relay mechanism (placeholder) or other histone marks associated with $\mathrm{H} 3 \mathrm{~K} 27 \mathrm{me} 3$ carry the information into the embryo. By contrast, we observe that most of the H3K4 methylation peaks present in Xenopus laevis embryos just before ZGA could be traced back to the homogeneous fraction of $\mathrm{H} 3 \mathrm{~K} 4$ methylation identified in sperm. In human a recent report also indicates that $\mathrm{H} 3 \mathrm{~K} 4 \mathrm{me} 3$ persists from fertilisation to post-ZGA stage embryos ${ }^{37}$. Altogether this suggests that sperm-derived modified histones contribute to the establishment of the embryonic epigenome prior to ZGA.

We find that the homogenous fraction of methylated histones in a Xenopus sperm population is transmitted through the first embryonic cell cycle and potentially through cell divisions of the developing embryos to regulate early embryonic gene expression. Defect in these epigenetic programming of sperm for embryonic development could be at the origin of case of idiopathic male infertility. In addition, the natural mechanisms of epigenetic information transmission from the sperm to the developing embryos might also be responsible for the maintenance of an epigenetic memory of somatic cell identity that characterise embryos generated by nuclear transfer ${ }^{2,38}$. By getting a better understanding of the processes underlying the transmission of paternal epigenetic information, we will be able to devise better strategies to erase somatic cell identity and improve cloning efficiency. 
a

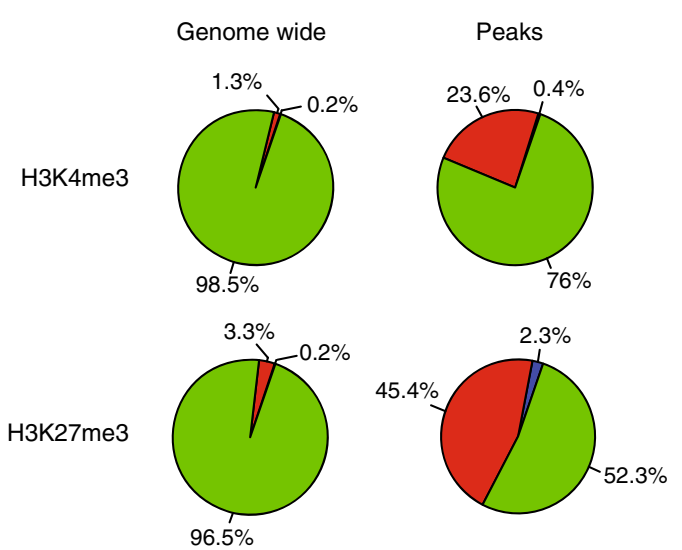

$\mathrm{HMD}>80 \%$

$20 \%<\mathrm{HMD}<80 \%$

HMD $<20 \%$
C
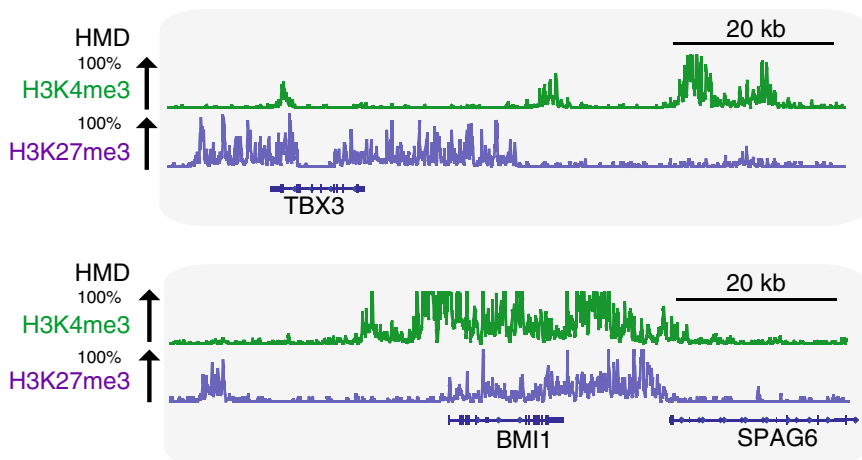

b

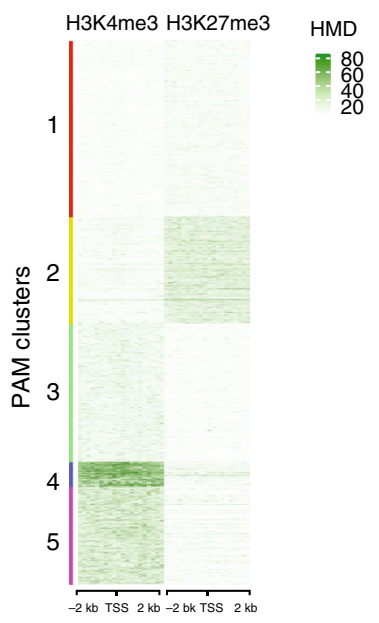

d

\begin{tabular}{cc|c|c|} 
& & $\begin{array}{c}\text { All } \\
\text { peaks }\end{array}$ & $\begin{array}{c}\mathrm{HMD}>80 \\
\text { peaks }\end{array}$ \\
\hline $\begin{array}{c}\text { \%Orthologues } \\
\text { marked } \\
\text { in both species }\end{array}$ & $\mathrm{H} 3 \mathrm{~K} 4 \mathrm{me} 3$ & $72.1 \%^{*}$ & $32 \%$ \\
\cline { 3 - 4 } & $\mathrm{H} 3 \mathrm{~K} 27 \mathrm{me} 3$ & $58.8 \%^{*}$ & $8 \%$ \\
\hline
\end{tabular}

e
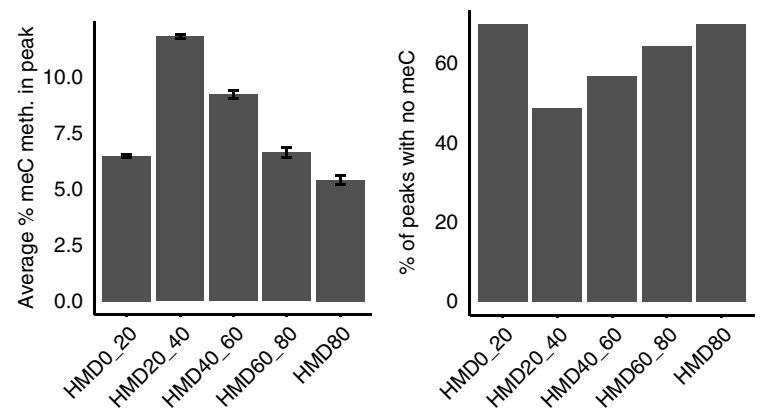

$\mathbf{f}$

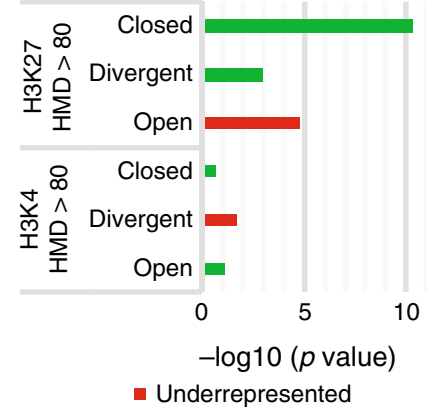

- Overrepressented g Proposed model for chromatin organization and homogeneous nucleosome reetention in sperm

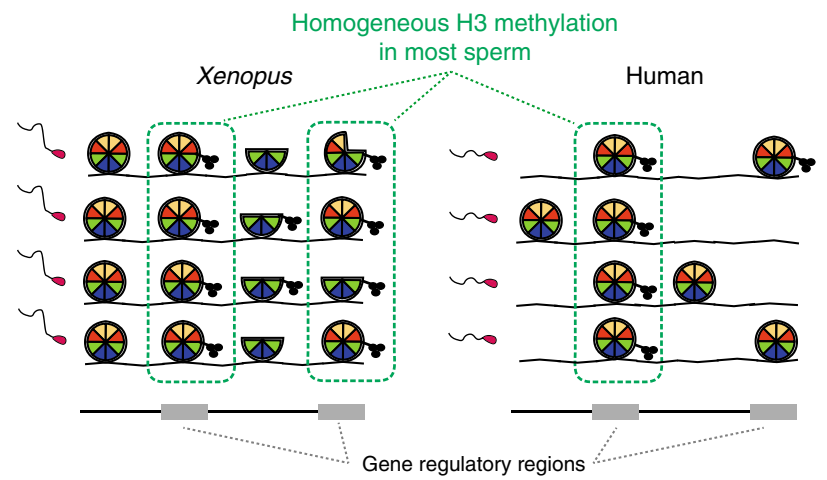

\section{Methods}

Experimental model and subject details. Mature Xenopus laevis males were obtained from Nasco (901 Janesville Avenue, PO Box 901, Fort Atkinson, WI 53538-0901; https://www.enasco.com/xenopus). Our work with Xenopus complied with all relevant ethical regulations for animal testing and research. This work is covered under the Home Office Project License PPL 70/8591 and frog husbandry and all experiments were performed according to the relevant regulatory standards.
Animals were kept in a Marine Biotech recirculating system at a density of one adult $/ 31$, with $10 \%$ water change per day. Water was sequentially filtered with mechanical pad sump filter, nitrifying bacteria filter, mechanical canister filter, carbon filter and UV sterilised. Water quality parameters were as follow: conductivity $1500 \mathrm{uS}$; temperature $17-22^{\circ} \mathrm{C}$; $\mathrm{PH} 6-8$. Photoperiod was set to $12 \mathrm{~h} \mathrm{ON} /$ $12 \mathrm{~h}$ OFF. Frogs are fed twice per week with Royal Horizon $4.5 \mathrm{~mm}$ pellets

(skretting, https://www.skrettingfishfeeds.co.uk/). Unconsumed food was removed 
Fig. 7 Homogeneous retention of methylated nucleosome in a human sperm population. a Percentage of the genome (left) and percentage of peaks (right) with different levels of H3K4 or H3K27 methylation density in human sperm. b PAM clustering of H3K4 and H3K27 HMD levels at promoter regions (TSS $+/-2 \mathrm{~kb}$ ) in human sperm. c Genome browser screenshots of TBX3 and BMI1 HMDs in human sperm. $\mathbf{d}$ Percentage of gene orthologues with peaks of histone methylation in both human and Xenopus sperm. e Barplots of the average percentage (\%) of $5 \mathrm{mC}$ methylation at $\mathrm{H} 3 \mathrm{~K} 27 \mathrm{me} 3$ peaks stratified by methylation level (left); error bars: sem; barplot of the percentage of H3K27me3 peaks showing absence of $5 \mathrm{mC}$ methylation (right) ( $5 \mathrm{mC}$ methylation: single-sperm bisulfite sequencing data from ref. ${ }^{31}$ ). $\mathbf{f}$ Barplots indicating $-\log 10$ ( $p$ value) for enrichment of sperm TSSs with HMD > 80 for H3K4 or H3K27 in set of genes with TSSs showing different chromatin accessibility level in eight cell embryos (open and closed corresponds to TSSs open or closed in all cells of a eight cell embryos), whereas divergent corresponds to TSSs either open or closed in different cells (ATAC-seq data from ref. ${ }^{31}$ ); $p$ values determined by $\chi^{2}$ proportion test evaluating if the proportion of gene of interest is higher (green) or lower (red) than the genome-wide proportion (i.e., expected proportion). $\mathbf{g}$ Model of epigenetic homogeneity in Xenopus and human sperm. The cartoon summarises the observed trends in retention of modified histones across the genome in those species. Source data related to $\mathbf{b}$ and $\mathbf{e}$ are provided as Source Data files.

10 min after the start of feeding. The researchers and the staff of the Gurdon Institute animal husbandry facility are trained in these experiments, and veterinarians monitor the health status of the animals.

Xenopus sperm collection. Xenopus sperm collection was performed as described before $^{2}$. For each round of sperm purification, testes from six adult Xenopus laevis males were isolated and manually cleaned from blood vessels and fat bodies in $1 \times$ Marc's modified ringers (MMR, $100 \mathrm{mM} \mathrm{NaCl}, 2 \mathrm{mM} \mathrm{KCl}, 1 \mathrm{mM} \mathrm{MgSO}_{4}, 2 \mathrm{mM}$ $\mathrm{CaCl}_{2}, 3 \mathrm{mM}$ HEPES, $\mathrm{pH}$ 7.4) using forceps and paper tissues. It is crucial to clean the testes well from any non-testicular tissues, as otherwise the cells released from the tissues may negatively affect the final purity of isolated cells. Subsequently, testes were torn into small pieces with forceps and homogenised with 2-3 strokes of a dounce homogeniser (tissue from one testis at a time). The cell suspension was then filtered to remove tissue debris and cell clumps (CellTrics, cat. 04-0042-2317) and spun down at $800 \mathrm{rcf}, 4^{\circ} \mathrm{C}$, for $20 \mathrm{~min}$. Supernatant was discarded and the cell pellet was resuspended in $12 \mathrm{~mL}$ of $1 \times \mathrm{MMR}$. If any red blood cells were visible at the bottom of the pellet (a result of incomplete removal of blood vessels), only the uncontaminated part of the pellet was recovered, taking extreme care not to disturb the red blood cells. Subsequently, step gradients of iodixanol (Optiprep; Sigma,

D1556; 60\% iodixanol in water) in $1 \times$ MMR final were manually prepared in prechilled $14 \mathrm{~mL}$ ultra-clear centrifuge tubes (Beckman Coulter, \#344060) in the following order from the bottom to the top of the tube: $4 \mathrm{~mL}$ of $30 \%$ iodixanol, $1 \mathrm{~mL}$ of $20 \%$ iodixanol, $5 \mathrm{~mL}$ of $12 \%$ iodixanol (all in $1 \times \mathrm{MMR}$ ) and $2 \mathrm{~mL}$ of cell suspension in $1 \times$ MMR on top. Gradients were spun down in a pre-chilled SW40Ti rotor at $7500 \mathrm{rpm}(10,000 \mathrm{~g}), 4^{\circ} \mathrm{C}$, for $15 \mathrm{~min}$, deceleration without brake (Beckman Coulter Ultra-centrifuge, Optima L-100XP). The pelleted fraction, containing mature sperm, was collected. Collected fractions were diluted six times with $1 \times$ MMR and collected by spinning first at $805 \mathrm{rcf}, 4^{\circ} \mathrm{C}$, for $20 \mathrm{~min}$ and respinning at $3220 \mathrm{rcf}, 4^{\circ} \mathrm{C}$, for $20 \mathrm{~min}$ to pellet remaining cells. Pelleted cells were subsequently permeabilized with Digitonin $(10 \mathrm{mg} / \mathrm{mL}$ as a final concentration, Sigma, D141) for $5 \mathrm{~min}$ at room temperature (RT) as detailed before ${ }^{39}$.

Human-sperm collection. All human sperm samples were processed in accordance to ReproMed Ireland's standard procedures and ethical approval was obtained from the University College Dublin Human Ethics Committee (HREC) (protocol number LS-16-53-ODoherty-Fair). The approval process entailed independent peer review along with approval from the HREC. Human-sperm samples were donated to the research project by informed consent. Written informed consent was obtained from male partners of expectant couples/couples that recently had a baby (within 6 months of sample donation) that donated fresh sperm samples following 3 days of abstinence. Before giving consent, donors were provided with all of the necessary information about the research project and contact information for the project lead. Specifically, patients signed a consent form authorising the use of their sperm samples for future research purposes, including molecular and epigenetic analyses, and for the results of these studies to be published in scientific journals. No financial inducements were offered for donation.

Chromatin was prepared from fresh ejaculates donated from men with proven fertility. Men were deemed fertile based on the following parameters; female partners are currently pregnant or have given birth within 6 months of sample production. Semen samples were collected from men aged between 30 and 35 years old. Ejaculates were maintained at $37^{\circ} \mathrm{C}$ for $10 \mathrm{~min}$ immediately following production. A $10 \mu \mathrm{l}$ aliquot of each fresh ejaculate was subjected to routine semen analysis prior to processing and all samples were in accordance with the World Health Organization guidelines (World Health Organization. WHO laboratory manual for the examination and processing of human semen (5th ed.), WHO Press (2010)) for normal semen samples (sperm density, total number, motility, morphology and semen volume). The recorded parameters for sperm preparations used in this study were within the following range: progressive motility $(\mathrm{PR})=$ $74-81 \%$; non-progressive motility $(\mathrm{NP})=10-13 \%$; immotile $(\mathrm{IM})=9-11 \%$; total motility $(\mathrm{PR}+\mathrm{NP})=87-91 \%$.

Motile spermatozoa were purified on a discontinuous Percoll gradient (Pharmacia, Uppsala, Sweden), as outlined previously ${ }^{40}$. Gradient-purified spermatozoa were quantified, resuspended in Hepes-buffered Tyrode's medium
(Sigma). Permeabilization of sperm nuclei was performed with Digitonin following the same procedure as for Xenopus samples.

Xenopus cell culture. Cell line XL-177 was derived from tadpole epithelium of $X$ laevis ${ }^{41}$. Cultured cells were maintained in medium containing L-15 (SIGMA L1518), sterile water and FBS (6:3:1vol/vol) and supplemented with $100 \mu \mathrm{l}$ penicillin/streptomycin. Cells were grown at $23^{\circ} \mathrm{C}$ in gelatin-coated dish that were sealed. Confluent culture of cells were split 1:3 to 1:6 following trypsin digestion.

Interphase egg extract preparation. Eggs were collected in $1 \times$ MMR, de-jellied with $0.2 \times$ MBS (Modified Barth's Saline) including 2\% cysteine (Sigma, W326305) ( $\mathrm{pH}$ was adjusted to 7.8 using $10 \mathrm{~N} \mathrm{NaOH}$ ) and washed with $0.2 \times$ MMR. Subsequently, eggs were activated for $3 \mathrm{~min}$ at RT with $0.2 \times$ MMR supplemented with $0.2 \mu \mathrm{g} / \mathrm{mL}$ calcium ionophore (Sigma, C7522). Eggs were rinsed with $0.2 \times \mathrm{MMR}$ and subsequently all abnormal or not-activated eggs were removed. Eggs were washed with $50 \mathrm{~mL}$ of ice-cold extraction buffer (EB) $(5 \mathrm{mM} \mathrm{KCl}, 0.5 \mathrm{mM} \mathrm{MgCl} 2$ $0.2 \mathrm{mM}$ DTT, $5 \mathrm{mM}$ Hepes pH 7.5) supplemented with protease inhibitors (PIs) (Roche, 11873580001), transferred into centrifugation tube (Thinwall. UltraClear TM, $5 \mathrm{~mL}, 13 \times 51 \mathrm{~mm}$ tubes, Beckman Coulter Inc., UK; 344057) and supplemented with $1 \mathrm{~mL}$ of EB buffer with PI and $100 \mu \mathrm{g} / \mathrm{mL}$ of cytochalasin B (Sigma, C2743) and placed on ice for $10 \mathrm{~min}$. Subsequently, eggs were spun briefly at $350 x$ $\mathrm{g}$ for $1 \mathrm{~min}$ at $4 \mathrm{C}$ (SW55Ti rotor, Beckman Coulter Ultra-centrifuge, Optima L$100 \mathrm{XP}$ ) and excess buffer was discarded. Eggs were then spun at $18,000 \times \mathrm{g}$ for 10 $\mathrm{min}$ at $1 \mathrm{C}$, the extract was collected with a needle, transferred to a fresh, prechilled tube, supplemented with PI and $10 \mu \mathrm{g} / \mathrm{mL}$ of cytochalasin B, and respun using the same conditions. Extract was collected with a needle and used fresh for the replication assay.

Expression and purification of Delta-Geminin. pET28 Delta-Geminin were transformed into E.coli and transformants were cultured overnight in $5 \mathrm{ml}$ of LB medium, containing $50 \mu \mathrm{g} / \mathrm{ml}$ kanamycin and $30 \mu \mathrm{g} / \mathrm{ml}$ chloramphenicol. Overnight cultures were transferred into $250 \mathrm{ml}$ of LB medium without glucose and antibiotics and incubated for $2-2.5 \mathrm{~h}$ at 37 . One hundred microlitres of $1 \mathrm{M}$ isopropyl 1-thio-beta-D-galactopyranoside was added into culture to induce recombinant protein expression. After $2 \mathrm{~h}$ induction, cells were collected by centrifugation. Cell pellets were suspended into $30-40 \mathrm{ml}$ of MilliQ water and transferred into $50 \mathrm{ml}$ tubes. After centrifugation, supernatant was removed and pellets were stored at $-80^{\circ} \mathrm{C}$. Frozen pellets were suspended into $5 \mathrm{ml}$ of Dicis buffer (300 mM NaCl, $150 \mathrm{mM}$ KoAC, $20 \mathrm{mM}$ Tris, pH7.5, $2 \mathrm{mM} \mathrm{MgCl} 2,10 \%$ glycerol, $0.01 \%$ NP40), with $0.1 \%$ NP40 and PIs, on ice. The suspensions were sonicated with Vibra-Cell Ultrasonic Processor (SONICS) for six times $15 \mathrm{~s}$ on and off cycles. Sonicated samples were centrifuged at $15,000 \mathrm{rpm}$ for $10 \mathrm{~min}$ at $4{ }^{\circ} \mathrm{C}$ and supernatants were collected. Ni-NTA agarose (Qiagen, 30210) was washed with 5 $\mathrm{ml}$ of Dicis buffer for three times in open column. Equilibrated Ni-NTA agarose was transferred into supernatants and rotated for $1 \mathrm{~h} \mathrm{at} 4^{\circ} \mathrm{C}$. Agarose beads were transferred into open column and washed twice with $10 \mathrm{ml}$ of Dicis buffer with 20 $\mathrm{mM}$ imidazole. Bound protein was eluted with Dicis buffer with either $100 \mathrm{mM}$ or $200 \mathrm{mM}$ imidazole for three times, respectively. Three fractions with highly concentrated delta-Geminin were pooled. Fractions were applied to PD10 column (GE Healthcare) equilibrated with buffer containing $10 \mathrm{mM}$ Tris-HCl, pH8.0, $0.5 \mathrm{M}$ $\mathrm{NaCl}, 5 \%$ glycerol and eluted with $3 \mathrm{ml}$ of buffer.

DNA replication in egg extracts. Freshly prepared egg extracts were supplemented with $0.005 \mathrm{mg} / \mathrm{ml}$ creatine kinase (Roche, 10127566001$), 0.375 \mathrm{mM}$ creatine phosphate (Roche, 10621714001), $0.05 \mathrm{mM}$ ATP (Roche, 10519979001), 0.005 mM EGTA, $1 \mathrm{mM} \mathrm{MgCl}$. In some experiments, delta-geminin was added (final concentration $1.5 \mu \mathrm{g} / \mathrm{ml}$ ) to egg extract to inhibit DNA replication. Permeabilized sperm cells were added to a final concentration of 1000 nuclei/ $\mu$ l of extract and incubated at RT for $2 \mathrm{~h}$ with gentle tapping every $10 \mathrm{~min}$. The reaction was stopped by adding 10 volumes of ice-cold Egg Lysis Buffer-Chromatin Isolation Buffer (ELB-CIB, $10 \mathrm{mM}$ Hepes pH 7.8, $250 \mathrm{mM}$ sucrose, $2.5 \mathrm{mM} \mathrm{MgCl} 2,50 \mathrm{mM} \mathrm{KCl}$, $1 \mathrm{mM}$ DTT, $1 \mathrm{mM}$ EDTA, $1 \mathrm{mM}$ spermidine, $1 \mathrm{mM}$ spermine, $0.1 \%$ Triton X-100, 
$10 \mathrm{mM}$ sodium butyrate, $1 \times$ EDTA-free PI Cocktail (Roche, 05056489001$)$ ) following Wang et al. ${ }^{42}$, with slight modifications. Chromatin was isolated via centrifugation at $4000 \mathrm{rpm}$ for $5 \mathrm{~min}$ through a $0.3 \mathrm{~mL}$ sucrose cushion of ELB-CIB with $0.5 \mathrm{M}$ sucrose underlayered in the tube. The pellet was washed once with ELB-CIB plus $250 \mathrm{mM} \mathrm{KCl}$. Samples were aliquoted (0.5-1 million of cells per tube) and flash frozen in liquid nitrogen.

Quantification of DNA replication activity in egg extract. To visualise replication in individual nuclei, $33 \mu \mathrm{M}$ rhodamine dUTP (Roche, 11534378910) was added at the indicated times $(20,40,60,90 \mathrm{~min}$ after incubation) for $5 \mathrm{~min}$ as indicated, and the reaction was stopped with $1 \times$ PBS and fixed in $4 \%$ paraformaldehyde. The reaction was spun through a $30 \%$ sucrose cushion in PBS. The sperm cells were rinsed twice in $1 \times$ PBS for $10 \mathrm{~min}$ and mounted in Vectashield mounting medium with DAPI (Vector laboratories, H-1200). Images were acquired with a Zeiss 510 META confocal LSM microscope (Zeiss). Counting of rhodamine positive cells and measurement of rhodamine signal intensity were performed in Image J software.

\section{Sperm chromatin immunoprecipitation (ChIP). Chromatin fractionation and} ChIP were performed as described before 2,43 with slight modifications. Eighty microlitre of Magnetic beads (M-280 Sheep anti-rabbit IgG, Invitrogen, \#11204D) were used per reaction and all wash steps were carried out with a magnet. Beads were washed with $1 \mathrm{ml}$ of TE pH 8.0, lysis buffer (LB)(1:1 mixture of Buffer 1 and MNase buffer, see below), and incubated in $1 \mathrm{ml}$ of LB with $100 \mu \mathrm{lof} 10 \mathrm{mg} / \mathrm{ml}$ BSA at $4{ }^{\circ} \mathrm{C}$ for $30 \mathrm{~min}$ ('pre-blocking'). Pre-blocked beads were washed with $1 \mathrm{ml}$ of LB twice and resuspend in $80 \mu \mathrm{l}$ of LB. Half of beads were incubated with antibody overnight and leftovers were stored in $4^{\circ} \mathrm{C}$ for 'pre-clear chromatin' step. For ChIP, following antibodies were used: anti-H3K4me3 (Abcam, ab8580) and anti-H3K27me3 (kind gift from Dr Thomas Jenuwein). Egg extract-treated sperm chromatin was resuspended in $50 \mu \mathrm{l}$ of Buffer $1(0.3 \mathrm{M}$ Sucrose, $15 \mathrm{mM}$ Tris $\mathrm{pH} 7.5$, $60 \mathrm{mM} \mathrm{KCl}, 15 \mathrm{mM} \mathrm{NaCl}, 5 \mathrm{mM} \mathrm{MgCl}, 0.1 \mathrm{mM}$ EGTA, $0.5 \mathrm{mM}$ DTT) and added $50 \mu \mathrm{l}$ of Buffer 1 with detergent (Buffer 1 including $0.5 \%$ NP40 and 1\% NaDOC). Samples were incubated for $10 \mathrm{~min}$ on ice. One hundred microlitres of MNase buffer ( $0.3 \mathrm{M}$ Sucrose, $85 \mathrm{mM}$ Tris, $3 \mathrm{mM} \mathrm{MgCl}, 2 \mathrm{mM} \mathrm{CaCl}, 2.5 \mathrm{U}$ of micrococcal nuclease: Roche 10107921001) was added in to each tube ( 0.5 million of cells per tube). Tubes were incubated at $37^{\circ} \mathrm{C}$ for $30 \mathrm{~min}$ in pre-warmed water bath. Reaction was stopped by adding $2 \mu \mathrm{l}$ of $0.5 \mathrm{M}$ EDTA pH 8.0 in the same order as started. Tubes were vortexed and placed on ice for at least $5 \mathrm{~min}$. Supernatant and pellet were separated by centrifugation at $13,000 \mathrm{rpm}$ for $10 \mathrm{~min}$ at RT. Beads (stored at $4{ }^{\circ} \mathrm{C}$ for pre-clear chromatin) were washed with $1 \mathrm{ml}$ of $\mathrm{LB}$ twice. Supernatant and EDTA-free protenase inhibitor cocktail were added into the beads and rotating on the wheel at $4^{\circ} \mathrm{C}$ for $60 \mathrm{~min}$. Ten percent of volume of pre-cleared chromatin was taken as 'input' and stored at $4{ }^{\circ} \mathrm{C}$. Antibody-conjugated beads were washed with $1 \mathrm{ml}$ of LB twice. Pre-cleared chromatin were added to washed beads and incubated at $4{ }^{\circ} \mathrm{C}$ for $6 \mathrm{~h}$. After incubation, beads were washed with $1 \mathrm{ml}$ of washing buffer A ( $50 \mathrm{mM}$ Tris- $\mathrm{HCl} \mathrm{pH} 7.5,10 \mathrm{mM}$ EDTA and $75 \mathrm{mM} \mathrm{NaCl})$ on the wheel at $4{ }^{\circ} \mathrm{C}$ for $5 \mathrm{~min}$ and buffer was discarded carefully. Subsequently, beads

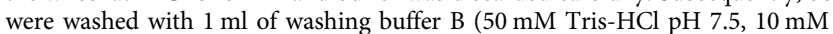
EDTA and $125 \mathrm{mM} \mathrm{NaCl}$ ) and buffer was discarded carefully. Another $1 \mathrm{ml}$ of washing buffer $\mathrm{B}$ was added and transferred to $1.5 \mathrm{ml}$ protein lo-bind tubes (Eppendorf, 0030108116) with beads. Buffer was discarded carefully. One hundred and fifty microlitres of elution buffer (1:9 mixture of $10 \%$ SDS and TE) was added. Tubes were placed at $25^{\circ} \mathrm{C}$ on the Eppendorf thermomixer and shaked at $800 \mathrm{rpm}$ for $15 \mathrm{~min}$. Supernatant were taken and transferred to the new tube using magnetic stand. Another $150 \mu \mathrm{l}$ of elution buffer was added and repeated this step (in total $300 \mu \mathrm{l}$ ). Input samples were diluted to $300 \mu \mathrm{l}$ total by adding TE. Two microlitres of $2 \mathrm{mg} / \mathrm{ml}$ RNase A (heat-inactivated or DNase-free) was added and incubated at $37^{\circ} \mathrm{C}$ for $30 \mathrm{~min}$. Four microlitres of $10 \mathrm{mg} / \mathrm{ml}$ Proteinase $\mathrm{K}$ was added and incubated at $55^{\circ} \mathrm{C}$ overnight. After incubation, tubes were shortly spun. Three hundred microlitres of Phenol/chloroform were added and vortexed for $30 \mathrm{~s}$. Samples were centrifuged at 13,000 rpm for $10 \mathrm{~min}$ at RT. One microlitre of Glycogen, 1/ 10 volume of $\mathrm{NaAcetate}$ and 2 volume of $100 \% \mathrm{EtOH}$ were added and vortexed. Tubes were stored on dry ice for 20-30 min. After freezing, tubes were centrifuged at $13,000 \mathrm{rpm}$ for $30 \mathrm{~min}$ at $4{ }^{\circ} \mathrm{C}$. Supernatant was discarded carefully and $500 \mu \mathrm{l}$ of $70 \%$ $\mathrm{EtOH}$ was added. Tubes were centrifuged at $13,000 \mathrm{rpm}$ for $10 \mathrm{~min}$ at $4^{\circ} \mathrm{C}$. Pellets were dried and suspended in $17 \mu \mathrm{l}$ of $\mathrm{ddH}_{2} \mathrm{O}$. DNA was excised and subjected to library preparation with a TruSeq DNA Kit (Illumina, FC-121-2001).

Internal standard calibrated ChIP (ICe-ChIP). Most procedures were performed following the ChIP section protocol. For internal standard calibration, semisynthetic nucleosomes were spiked in just before MNase digestion. We used the semi-synthetic standards used in Grzybowski et al. ${ }^{18}$ and provided by the Ruthenburg's lab. We spiked in the standards aiming for the second lowest concentration of the barcoded nucleosomes to be at the same concentration as the genome count (to that end we simply multiply the amount of the nuclei in the sample with the number of genome copies per nucleus ( 2.5 for dividing diploid; 2 for stationary diploid; 1 for haploid). We then add the amount of the ladder equivalent to the member representing the $5 \%$ or $10 \%$ of the ladder so that some standards will be below and above the expected genome coverage). Sperm chromatin and semi-synthetic nucleosomes were digested with $2.5 \mathrm{U}$ (Xenopus) and $0.5 \mathrm{U}$ (human) of MNase for $30 \mathrm{~min}$ at $37^{\circ} \mathrm{C}$. The following antibodies were used: anti-H3K4me3 (Abcam, ab8580) and anti-H3K27me3 (kind gift from Dr Thomas Jenuwein). Apparent inflation of HMD values for H3K27me3 beyond what is physically possible indicates off-target binding by the antibody, most likely $\mathrm{H} 3 \mathrm{~K} 27 \mathrm{me} 2$ as we have anecdotally observed in prior ICe-ChIP experiments, or a consequence of PCR-duplicate removal's bias for excluding IP versus input reads. As a consequence, we express these data as apparent HMD \%.

Embryos ChIP. ChIP was performed as described previously ${ }^{44,45}$ with the following modifications. Blastula (stage 7) embryos were generated by in vitro fertilisation. For each ChIP experiment, 20-30 embryos were fixed in $2 \mathrm{~mL}$ of $1 \%$ formaldehyde in $1 \times$ MMR for $15-25 \mathrm{~min}$ at RT, followed by four washes with $1 \mathrm{ml}$ of $1 \times$ MMR and equilibration in $500 \mu \mathrm{l}$ HEG solution $(50 \mathrm{mM}$ HEPES-KOH pH 7.5, $1 \mathrm{mM}$ EDTA, $20 \%$ Glycerol) at $4{ }^{\circ} \mathrm{C}$, then excess buffer was removed and samples were frozen at $-80^{\circ} \mathrm{C}$. To extract chromatin, the samples were transferred to $2 \mathrm{ml}$ tube or $15 \mathrm{ml}$ Falcon tube and homogenised in 200-250 $\mu$ lof sonication buffer (20 mM Tris-HCl pH 8.0, $70 \mathrm{mM} \mathrm{KCl}, 1 \mathrm{mM}$ EDTA pH 8.0, 10\% Glycerol, $5 \mathrm{mM}$ DTT, $0.125 \%$ NP40, $1 \times$ complete PIs), by pipetting up and down in a $1 \mathrm{ml}$ pipette tip. Two hundred and fifty microlitres of diagenode beads were transferred to diagenode falcon tube (Diagenode, C1020031). Seven hundred and fifty microlitres of embryo lysates were added and diagnode falcons were transferred to the sonicator bath (diagnode bioruptor). Sonication is carried out in 30 cycles (with $30 \mathrm{~s}$ on/off cycles). Sonicated embryo extract was transferred into eppendorf tubes. Chromatin was collected by centrifugation for $5 \mathrm{~min}$ at top speed in tabletop centrifuge at $4{ }^{\circ} \mathrm{C}$. Chromatin extract was transferred to new tube and stored in ice. Before ChIP, $50 \mu \mathrm{l}$ (20\% of extract) of chromatin was taken as an input control and stored at $4{ }^{\circ} \mathrm{C}$ on ice. For each ChIP reaction, $200 \mu$ lof chromatin extract was mixed with $1-5 \mu \mathrm{g}$ of antibodies and incubated for $2 \mathrm{~h}$ at $4^{\circ} \mathrm{C}$ on a rotating wheel, in the mean time beads were prepared. Twenty microlitres of beads (Dynabeads M280 sheep anti-rabbit IgG or Protein A/G dynabeads) were taken and washed for three times in $1 \times$ PBS containing $1 \%$ BSA and once in ChIP incubation buffer (50 mM Tris-HCl pH 8.0, 100 mM NaCl, 2 mM EDTA, 1 mM DTT, 1\% NP40, $1 \times$ complete PIs). Beads were resuspended in $100 \mu \mathrm{l}$ of ChIP incubation buffer per reaction and added to chromatin-antibody mix. Samples were incubated at $4{ }^{\circ} \mathrm{C}$ with overnight rotating. After reaction, supernatant was removed. Beads were sequentially washed with $1 \mathrm{ml}$ of wash buffer $1(50 \mathrm{mM}$ Tris- $\mathrm{HCl}$ pH8.0, $100 \mathrm{mM}$ $\mathrm{NaCl}, 2 \mathrm{mM}$ EDTA, $1 \mathrm{mM}$ DTT, $1 \%$ NP40, $0.1 \%$ doxycholate, $1 \times$ complete PIs) for $5 \mathrm{~min}$ on ice, and supernatant was removed subsequently. Washing was performed with this step: $1 \mathrm{ml}$ wash buffer $2(50 \mathrm{mM}$ Tris- $\mathrm{HCl} \mathrm{pH8.0,500} \mathrm{mM} \mathrm{NaCl}, 2 \mathrm{mM}$ EDTA, $1 \mathrm{mM}$ DTT, $1 \%$ NP40, $0.1 \%$ deoxycholate, $1 \mathrm{x}$ complete PIs), $1 \mathrm{ml}$ of wash buffer 3 (50 mM Tris-HCl pH8.0, $100 \mathrm{mM} \mathrm{NaCl}, 250 \mathrm{mM} \mathrm{LiCl}, 2 \mathrm{mM}$ EDTA, $1 \mathrm{mM}$ DTT, $1 \%$ NP40, $0.1 \%$ deoxycholate, $1 \times$ complete PIs), $1 \mathrm{ml}$ of wash buffer 1 and $500 \mu \mathrm{l}$ of TE buffer (10 mM Tris-HCl, pH 8.0, $1 \mathrm{mM}$ EDTA). After washing, supernatant was removed. Four hundred microlitres of elution buffer was added to the beads, and $350 \mu \mathrm{l}$ of elution buffer to the input. Sixteen microlitres of $5 \mathrm{M} \mathrm{NaCl}$ was added to each tube. Cross-links were reversed by incubating for $5 \mathrm{~h}$ at $65^{\circ} \mathrm{C}$ in a thermomixer shaking at $1000 \mathrm{rpm}$. Eight microlitres of RNaseA (DNase-free, $10 \mathrm{mg} / \mathrm{ml}$ ) was added to $400 \mu \mathrm{l}$ of reaction and incubated for $30 \mathrm{~min}$ at $37^{\circ} \mathrm{C}$. Four hundred microlitres of Phenol/chloroform/isoamylalcohol (25:24:1) pH 8.0 and mixed using vortex mixer for $30 \mathrm{~s}$. Samples were centrifuged at RT for $3 \mathrm{~min}$ with top speed. This extraction step was repeated again. One hundred microlitres of chloroform was added and mixed by vortex mixer for $30 \mathrm{~s}$. Samples were centrifuged at RT for $3 \mathrm{~min}$ at top speed. Aqueous upper phase was transferred to a new tube. For ethanol precipitation, $3 \mu \mathrm{l}$ of glycogen $(20 \mathrm{mg} / \mathrm{ml}), 40 \mu \mathrm{l}$ of $3 \mathrm{M}$ NaAcetate $\mathrm{pH} 5.2$ and $1200 \mu \mathrm{l}$ of ethanol (96\%) were added. Precipitation was performed overnight at $-20^{\circ} \mathrm{C}$ or for $20-30 \mathrm{~min}$ on dry ice. Samples were centrifuged at top speed for $10 \mathrm{~min}$. Supernatant was removed and pellet was washed with $1 \mathrm{ml}$ of cold ethanol (70\%). Samples were centrifuged at top speed for $10 \mathrm{~min}$. This washing step was repeated again. All supernatant was removed and pellet was air-dried for 10-15 min. Pellet was dissolved in $50 \mu \mathrm{l}$ of $\mathrm{ddH}_{2} \mathrm{O}$.

Library preparation and sequencing. ChIP samples were subjected for ChIP-seq library preparation using the TruSeq DNA kit (Illumina, FC-121- 2001) and Agencourt AMPure XP beads (Beckman coulter, A63881) with slight modifications. After end repair, A-tailing and adaptor ligation, DNA fragments were purified with two volumes of beads. Purified DNA was amplified by $18-22$ cycle of PCR cycle and size selection was performed. Greater than 370 bp DNA fragments were removed with 0.7 volume of beads, these selected DNA was recovered with 1.8 volume of beads, and $>250$ bp DNA fragments were collected with 1.0 volume of beads.

DNA length was analysed on a D1000 screen tape (Agilent, 5067-5582) using D1000 sample buffer (Agilent, 5067-5583) on an Agilent 2200 tape station. DNA quantity was analysed on a Qubit dsDNA HS assay kit (Invitrogen, Q32851) using Qubit system (Invitrogen). Single-end 50 bp sequencing was performed for ChIPseq libraries of egg extract-treated sperm and blastula DNA, and paired-end $32 \mathrm{bp}$ sequencing for ICeChIP-seq libraries of Xenopus and human sperm DNA on a HiSeq 1500 sequencer (Illumina). 
Chromatin particles separation on linear sucrose gradient. Xenopus sperm chromatin was digested with MNase as described ${ }^{2}$. Five and fifteen percent sucrose buffer (5\%: $10 \mathrm{mM}$ NaCacodylate pH7, $1 \mathrm{mM}$ EDTA, $0.5 \mathrm{mM}$ EGTA, $50 \mathrm{mM} \mathrm{KCl}$, $5 \%$ (w/v) sucrose, $0.5 \mathrm{mM}$ PMSG, $5 \mathrm{mM} 2$-mercaptoethanol and $1 \times$ PI) (15\%: same as $5 \%$ but with $15 \%(\mathrm{w} / \mathrm{v})$ sucrose instead) were prepared following Ruthernburg's lab website protocol with slight modification (http://ruthenlab.org/web/Protocols. html). $5.5 \mathrm{ml}$ of $15 \%$ sucrose buffer was transferred to $14 \mathrm{ml}$ tube (Beckman coulter, 344060 ) and $5.5 \mathrm{ml}$ of $5 \%$ sucrose buffer was layered carefully. Tubes were leaned for $3 \mathrm{~h}$ at RT to make linear gradient. One millilitre of digested sperm chromatin was loaded on each tube. For nucleosome and subnucleosome separations, tubes were centrifuged at $36,000 \mathrm{rpm}$ for $15-16 \mathrm{~h}$ at $4{ }^{\circ} \mathrm{C}$. After centrifugation, $250 \mu \mathrm{l}$ of each fraction was collected carefully starting from the top of the gradient. Fifty microlitres of each fraction was collected for DNA extraction. DNA was extracted by the Quiaquick DNA extraction kit (Qiagen, 28304), and DNA length was analysed on D1000 screentape (Agilent, 5067-5582), according to manufacturer instructions. Fraction containing 150 bp length DNA was treated as 'nucleosome fraction' and 70-110 bp length DNA was treated as 'subnucleosome fraction'. The remaining part of the fractions was pooled depending on DNA length. Proteins were precipitated by incubating with 20\% TCA on a rotating wheel for $3 \mathrm{~h}$ at $4{ }^{\circ} \mathrm{C}$. Proteins were pelleted by centrifugation at $10,000 \mathrm{rpm}$ for $15 \mathrm{~min}$ at $4^{\circ} \mathrm{C}$. Pellets from each biological replicate were washed with ice-cold acetone twice and dried. Five subnucleosome and nucleosome fractions were taken for mass spectrometry analysis. Out of five, one replicate for each condition is doubled up in order to increase the signal.

Quantitative mass spectrometry. TCA precipitated protein pellets of fractions were suspended in buffer containing $100 \mathrm{mM}$ Triethylammonium bicarbonate/ $0.1 \%$, heated at $90^{\circ} \mathrm{C}$ for $5 \mathrm{~min}$ followed by bath sonication for $30 \mathrm{~s}$. Proteins were reduced with $2 \mu \mathrm{l}$ of $50 \mathrm{mM}$ tris-2-caraboxymethyl phosphine for $1 \mathrm{~h}$ at $60^{\circ} \mathrm{C}$ followed by alkylation with $1 \mu \mathrm{l}$ of $200 \mathrm{mM}$ methyl methanethiosulfonate for 10 $\mathrm{min}$ at RT. Proteins were digested overnight at $37^{\circ} \mathrm{C}$ using trypsin (Thermo Scientific) asprotease at ratio protein/trypsin $\sim 1: 30$. Protein digests were labelled with the TMT-10plex reagents (Thermo Scientific; Lot \#SA239882A) for $1 \mathrm{~h}$. The reaction was quenched with $8 \mu$ l of $5 \%$ hydroxylamine (Thermo Scientific) for 15 $\mathrm{min}$ at RT. Samples were mixed and subsequently fractionated using the basic $\mathrm{pH}$ Reversed-Phase Peptide Fractionation kit (Thermo Scientific). Fractions were dried and each fraction was reconstituted in $0.1 \%$ formic acid for liquid chromatography tandem mass spectrometry (LC-MS/MS) analysis.

\section{LC-MS/MS}

Peptide fractions were analysed on a Fusion Lumos Orbitrap. Mass spectrometer (Thermo Scientific) was coupled with RSLC nano Ultimate 3000 system. Peptides were trapped on a $100 \mu \mathrm{m}$ ID $\times 2 \mathrm{~cm}$ microcapillary C18 column $(5 \mu \mathrm{m}, 100 \mathrm{~A})$ followed by $2 \mathrm{~h}$ elution on a $75 \mu \mathrm{m} \mathrm{ID} \times 25 \mathrm{~cm} \mathrm{C18} \mathrm{RP} \mathrm{column}(3 \mu \mathrm{m}, 100 \mathrm{~A})$ with $5-45 \%$ acetonitrile gradient in $0.1 \%$ formic acid at $300 \mathrm{nl} / \mathrm{min}$ flow rate. In each data collection cycle, one full MS Orbitrap scan $(380-1500 \mathrm{~m} / \mathrm{z})$ was acquired at $120 \mathrm{~K}$ resolution, automatic gain control (AGC) setting of $3 \times 10^{5}$ and maximum injection time (MIT) of $100 \mathrm{~ms}$. Subsequent MS2 scans were acquired with a top speed approach using a 3-s duration. The most abundant ions were selected for fragmentation by collision induced dissociation (CID) with a collision energy of $35 \%$, an AGC setting of $1 \times 10^{4}$, a quadrupole isolation window of $0.7 \mathrm{Da}$ and MIT of $35 \mathrm{~ms}$ and detected in ion trap. Previously analysed precursor ions were dynamically excluded for $45 \mathrm{~s}$. During the MS3 analyses for TMT quantification, precursor ion selection was based on the previous MS2 scan and isolated using a 2.0 Da $m / z$ window. MS2-MS3 was conducted using sequential precursor selection methodology with the top 10 setting. HCD was used for the MS3, using 55\% collision energy. Reporter ions were detected using the Orbitrap at $50 \mathrm{~K}$ resolution, an AGC setting of $5 \times 10^{4}$ and MIT of $86 \mathrm{~ms}$.

Quantitative mass spectrometry data processing. The collected CID tandem mass spectra were processed with the SequestHT search engine against the Xenopus laevis proteome database on the Proteome Discoverer 2.1 software for peptide and protein identifications. The node for SequestHT included the following parameters: precursor mass tolerance $20 \mathrm{ppm}$, FRagment Mass tolerance $0.5 \mathrm{Da}$, dynamic modifications were methionine oxidation $(+15.995 \mathrm{Da})$, aspartamine and glutamine deamination $(+0.984 \mathrm{Da})$ and Static Modifications were TMT6plex at any NTerminus, K $(+229.163 \mathrm{Da})$ for the quantitative data. Methylthio at C $(+45.988)$ was included for the total proteome data. The Reporter Ion Quantifier node included a TMT 6plex (Thermo Scientific Instruments) Quantification Method, for MS3 scan events, HCD activation type, integration window tolerance $20 \mathrm{ppm}$ and integration method most confident centroid. The consensus workflow included S/ $\mathrm{N}$ calculation for TMT intensities, and the level of confidence for peptide identifications was estimated using the Percolator node with decoy database search. Strict FDR was set at $q$ value $<0.01$. Quantitative proteomics data were analysed by qPLEXanalyzer, an R Bioconductor package ${ }^{46}$. The raw peptide intensities were normalised by median-scaled protein histone $\mathrm{H} 4$ (Xelaev18026404m.g) intensities. Statistical analysis of differentially expressed protein was carried out using Limma moderated $t$-test.
Protein extraction and WB analysis. For protein extraction, $80 \mu \mathrm{l}$ of EB $(500 \mathrm{mM}$ Tris pH6.8, $500 \mathrm{mM} \mathrm{NaCl}, 1 \% \mathrm{NP} 40,0.1 \%$ SDS, $1 \%$ beta-Mercapthoethanol and PI cocktail) was used to homogenise 1 million of sperm per sample. Lysates were centrifuged for $10 \mathrm{~min}$ at $4^{\circ} \mathrm{C}$ and $16,000 \mathrm{~g}$. The supernatant was transferred to a fresh tube, mixed with $20 \mu \mathrm{l}$ of $5 \times$ loading buffer $(0.3 \mathrm{M}$ Tris- $\mathrm{HCl} \mathrm{pH} \mathrm{6.8,50 \%} \mathrm{(v/v)}$ glycerol, $1 \%(\mathrm{w} / \mathrm{v})$ SDS, $0.05 \%(\mathrm{w} / \mathrm{v})$ bromophenol blue and $3.2 \%(\mathrm{v} / \mathrm{v})$ betamercaptoethanol) and boiled at $100^{\circ} \mathrm{C}$ for $5 \mathrm{~min}$. All samples were centrifuged for $3 \mathrm{~min}$ at RT $(16,000 \mathrm{~g})$. The supernatant was then transferred to a new tube. Polyacrylamide gels ( $12 \%$ SDS) were loaded with $10-40 \mu$ of this supernatant. Gel electrophoresis and western blots were performed according to standard protocols. For blotting PVDF membranes, a semi-dry transfer system was used (30-40 min $25 \mathrm{~V})$. For the protein detection, following primary antibodies were used: antiH3K4me3 (1:1000, Abcam, ab8580), anti-H3K27me3 (1:1000, cell signalling, 9733), anti-H4 (1:1000, Abcam, ab31830), anti-H3 (1:1000, Cell signalling, 14269), antiH2A (1:1000, Millipore, 07-146), and anti-H2B (1:2000, Abcam, ab1790), antiXHMGN2 (1:1000, kind gift from Dr Robert Hock), anti-HMGB1 (1:1000, Sigma H9664). Blots were incubated with primary antibodies overnight at $4{ }^{\circ} \mathrm{C}$. For the secondary reactions, anti-rabbit (1:25000, Thermo Fisher, A21076) or anti-mouse IgG Alexa Fluor 680 (1:25000, Thermo Fisher, A21058), Goat anti-rabbit Alexa 800 (1:25,000, Thermo Fisher, A32735), IRDye 800CW Goat Anti-Mouse IgG (H + L) (LI-COR, 926-32210) or anti-rabbit IgG Horseradish peroxidase conjugated antibodies (Thermo Fisher, \#31460, Cat \#31466) were used and incubated for $1 \mathrm{~h}$ at RT. The signals were captured using the imaging system Odyssey (LI-COR) or Xray film after incubating with ECL Western Blotting Detection Reagents (GE healthcare, RPN2109).

Sequencing data processing. See supplementary methods and Supplementary data 9 .

Reporting summary. Further information on research design is available in the Nature Research Reporting Summary linked to this article.

\section{Data availability}

The data that support this study are available from the corresponding author upon reasonable request. The Xenopus laevis ChIP-seq have been deposited on GEO with accession number GSE125982. Customised codes and scripts are available on GitLab The mass spectrometry proteomics data have been deposited to the ProteomeXchange Consortium via the PRIDE ${ }^{47}$ partner repository with the dataset identifier PXD012853. Publicly available data were obtained from GEO with the following accession numbers: GSE75164, GSE76915, GSE73430 and GSE100272. The source data underlying Figs. 1a, b, d, e, 3a, b, d, e, 4c and 7b, e and Supplementary Figs. 1a-c, 2a, c, g, 3c, d, 4c, e and 8a are provided as a Source Data file. Source data are provided with this paper.

Received: 11 January 2019; Accepted: 20 June 2020;

Published online: 13 July 2020

\section{References}

1. Pasque, V., Jullien, J., Miyamoto, K., Halley-Stott, R. P. \& Gurdon, J. B. Epigenetic factors influencing resistance to nuclear reprogramming. Trends Genet. 27, 516-525 (2011)

2. Teperek M. et al. Sperm is epigenetically programmed to regulate gene transcription in embryos. Genome Res. 26, 1034-1046 (2016).

3. Kimura, Y. \& Yanagimachi, R. Mouse oocytes injected with testicular spermatozoa or round spermatids can develop into normal offspring. Development 121, 2397-2405 (1995).

4. Kurotaki Y. K. et al. Impaired active DNA demethylation in zygotes generated by round spermatid injection. Hum. Reprod. 30, 1178-1187 (2015).

5. Hammoud S. S. et al. Distinctive chromatin in human sperm packages genes for embryo development. Nature 460, 473-478 (2009).

6. Teperek M. et al. Sperm is epigenetically programmed to regulate gene transcription in embryos. Genome Res. 26, 1034-1046 (2016).

7. Wu, S. F., Zhang, H. \& Cairns, B. R. Genes for embryo development are packaged in blocks of multivalent chromatin in zebrafish sperm. Genome Res. 21, 578-589 (2011).

8. Erkek S. et al. Molecular determinants of nucleosome retention at CpG-rich sequences in mouse spermatozoa. Nat. Struct. Mol. Biol. 20, 868-875 (2013)

9. Siklenka K. et al. Disruption of histone methylation in developing sperm impairs offspring health transgenerationally. Science 350, aab2006 (2015).

10. Morozumi, K., Shikano, T., Miyazaki, S. \& Yanagimachi, R. Simultaneous removal of sperm plasma membrane and acrosome before intracytoplasmic sperm injection improves oocyte activation/embryonic development. Proc. Natl Acad. Sci. USA 103, 17661-17666 (2006).

11. McSwiggin, H. M. \& O’Doherty, A. M. Epigenetic reprogramming during spermatogenesis and male factor infertility. Reproduction 156, R9-R21 (2018). 
12. Jung Y. H. et al. Chromatin states in mouse sperm correlate with embryonic and adult regulatory landscapes. Cell Rep. 18, 1366-1382 (2017).

13. Yoshida K. et al. Mapping of histone-binding sites in histone replacementcompleted spermatozoa. Nat. Commun. 9, 3885 (2018).

14. Carone B. R. et al. High-resolution mapping of chromatin packaging in mouse embryonic stem cells and sperm. Dev. Cell 30, 11-22 (2014).

15. Saitou, M. \& Kurimoto, K. Paternal nucleosomes: are they retained in developmental promoters or gene deserts? Dev. Cell 30, 6-8 (2014).

16. Katagiri, C. \& Ohsumi, K. Remodeling of sperm chromatin induced in egg extracts of amphibians. Int J. Dev. Biol. 38, 209-216 (1994).

17. Mann, M., Risley, M. S., Eckhardt, R. A. \& Kasinsky, H. E. Characterization of spermatid/sperm basic chromosomal proteins in the genus Xenopus (Anura, Pipidae). J. Exp. Zool. 222, 173-186 (1982).

18. Grzybowski, A. T., Chen, Z. \& Ruthenburg, A. J. Calibrating ChIP-seq with nucleosomal internal standards to measure histone modification density genome wide. Mol. Cell 58, 886-899 (2015).

19. Shechter D. et al. Analysis of histones in Xenopus laevis. I. A distinct index of enriched variants and modifications exists in each cell type and is remodeled during developmental transitions. J. Biol. Chem. 284, 1064-1074 (2009).

20. Teperek M. et al. Sperm and spermatids contain different proteins and bind distinct egg factors. Int. J. Mol. Sci. 15, 16719-16740 (2014).

21. Hainer, S. J. \& Fazzio, T. G. Regulation of nucleosome architecture and factor binding revealed by nuclease footprinting of the ESC genome. Cell Rep. 13, 61-69 (2015).

22. Ramachandran, S., Ahmad, K. \& Henikoff, S. Transcription and remodeling produce asymmetrically unwrapped nucleosomal intermediates. Mol. Cell 68, 1038-1053.e4 (2017).

23. Lu F. et al. Establishing chromatin regulatory landscape during mouse preimplantation development. Cell 165, 1375-1388 (2016).

24. Gao L. et al. A novel role for Ascll in the regulation of mesendoderm formation via HDAC-dependent antagonism of VegT. Development 143, 492-503 (2016).

25. Huang X. et al. Zfp281 is essential for mouse epiblast maturation through transcriptional and epigenetic control of Nodal signaling. Elife 6, (2017).

26. Gaggioli, V., Le Viet, B., Germe, T. \& Hyrien, O. DNA topoisomerase IIalpha controls replication origin cluster licensing and firing time in Xenopus egg extracts. Nucleic Acids Res. 41, 7313-7331 (2013).

27. Tada, S., Li, A., Maiorano, D., Mechali, M. \& Blow, J. J. Repression of origin assembly in metaphase depends on inhibition of RLF-B/Cdt1 by geminin. Nat. Cell Biol. 3, 107-113 (2001).

28. Wohlschlegel J. A. et al. Inhibition of eukaryotic DNA replication by geminin binding to Cdt1. Science 290, 2309-2312 (2000).

29. Gao L. et al. Chromatin accessibility landscape in human early embryos and its association with evolution. Cell 173, 248-259.e15 (2018).

30. Reddington J. P. et al. Redistribution of H3K27me3 upon DNA hypomethylation results in de-repression of Polycomb target genes. Genome Biol. 14, R25 (2013)

31. Li L. et al. Single-cell multi-omics sequencing of human early embryos. Nat. Cell Biol. 20, 847-858 (2018).

32. Skvortsova, K., Iovino, N. \& Bogdanovic, O. Functions and mechanisms of epigenetic inheritance in animals. Nat. Rev. Mol. Cell Biol. 19, 774-790 (2018).

33. Zhang B. et al. Widespread enhancer dememorization and promoter priming during parental-to-zygotic transition. Mol. Cell 72, 673-686.e6 (2018).

34. Vastenhouw N. L. et al. Chromatin signature of embryonic pluripotency is established during genome activation. Nature 464, 922-926 (2010).

35. Murphy, P. J., Wu, S. F., James, C. R., Wike, C. L. \& Cairns, B. R. Placeholder nucleosomes underlie germline-to-embryo DNA methylation reprogramming. Cell 172, 993-1006.e13 (2018).

36. Hontelez et al. Embryonic transcription is controlled by maternally defined chromatin state. Nat. Commun. 6, 10148 (2015).

37. Xia W. et al. Resetting histone modifications during human parental-tozygotic transition. Science 365, 353-360 (2019).

38. Hormanseder E. et al. H3K4 methylation-dependent memory of somatic cell identity inhibits reprogramming and development of nuclear transfer embryos. Cell Stem Cell. 21, 135-143 (2017).

39. Smith S. J. et al. Xenopus laevis transgenesis by sperm nuclear injection. Nat. Protoc. 1, 2195-2203 (2006).

40. O'Doherty A. M. et al. Negative energy balance affects imprint stability in oocytes recovered from postpartum dairy cows. Genomics 104, 177-185 (2014).

41. Ellison et al. Developmental changes in keratin patterns during epidermal maturation. Dev. Biol. 11, 329-337 (1985).

42. Wang et al. Phosphorylation and arginine methylation mark histone $\mathrm{H} 2 \mathrm{~A}$ prior to deposition during Xenopus laevis development. Epigenetics Chromatin 7, 22 (2014).
43. Hisano M. et al. Genome-wide chromatin analysis in mature mouse and human spermatozoa. Nat. Protoc. 8, 2449-2470 (2013).

44. Gentsch, G. E. \& Smith, J. C. Investigating physical chromatin associations across the Xenopus genome by chromatin immunoprecipitation. Cold Spring Harb. Protoc. 2014, 483-497 (2014)

45. Akkers, R. C., Jacobi, U. G. \& Veenstra, G. J. Chromatin immunoprecipitation analysis of Xenopus embryos. Methods Mol. Biol. 917, 279-292 (2012).

46. Papachristou E. K. et al. A quantitative mass spectrometry-based approach to monitor the dynamics of endogenous chromatin-associated protein complexes. Nat. Commun. 9, 2311 (2018).

47. Vizcaino J. A. et al. Update of the PRIDE database and its related tools. Nucleic Acids Res. 44, 11033, https://doi.org/10.1093/nar/gkw880 (2016).

\section{Acknowledgements}

J.J. is funded from a Wellcome Trust grant (101050/Z/13/Z). M.O is funded from a Wellcome Trust (101050/Z/13/Z), MRC (MR/K011022/1) grant and postdoctoral fellowship from the Japan Society for the Promotion of Science (JSPS). A.S. is funded from a Wellcome Trust (101050/Z/13/Z) and MRC (MR/K011022/1) grant. All members of the Gurdon group acknowledge the core support provided by the Gurdon Institute core grant from Cancer Research UK (C6946/A14492) and the Wellcome Trust (092096/Z/ 10/Z). A.O.D. is supported by a grant from the Science Foundation Ireland Industry Fellowship (SFI:15/IFB/350). C.D.S. and V.N.R.F. are supported by Cancer Research UK. The Fusion Lumos Orbitrap mass spectrometer was purchased with the support from a Wellcome Trust Multi-user Equipment Grant (Grant \#108467/Z/15/Z). This study was supported by the National Institutes of Health (R01-GM115945) to A.J.R. We would like to thank the following people for providing reagents used in this study: Dr Julian Blow (pET28 Delta-Geminin plasmid), Dr Atsuya Nishiyama (help with geminin purification), Dr Robert Hock (anti-XHMGN2 antibody) and Dr Thomas Jenuwein (anti-H3K27me3 antibody).

\section{Author contributions}

Conceptualisation: J.J.; methodology: J.J., M.O., M.T., A.S., T.F., L.D. and C.D.S.; validation: J.J., M.O. and A.S.; formal analysis: A.S. and K.K.; investigation: M.O., J.J., E.H., M.T., V.G., E.F., M.S. and V.N.R.F.; resources: A.O.D., D.K., A.T.G. and A.J.R.; data curation: C.R.B. and A.S.; writing original draft: J.J.; writing review and editing: J.J., M.O., A.S., E.H., A.O.D., A.J.R., J.G. and V.G.; visualisation: J.J., M.O. and A.S.; supervision: J.J.; project administration: J.J.; funding acquisition: J.J., M.T. and J.G.

\section{Competing interests}

The authors declare no competing interests.

\section{Additional information}

Supplementary information is available for this paper at https://doi.org/10.1038/s41467020-17238-w.

Correspondence and requests for materials should be addressed to J.J.

Peer review information Nature Communications thanks Shunsuke Ishii and the other, anonymous, reviewer(s) for their contribution to the peer review of this work. Peer reviewer reports are available.

Reprints and permission information is available at http://www.nature.com/reprints

Publisher's note Springer Nature remains neutral with regard to jurisdictional claims in published maps and institutional affiliations.

Open Access This article is licensed under a Creative Commons Attribution 4.0 International License, which permits use, sharing, adaptation, distribution and reproduction in any medium or format, as long as you give appropriate credit to the original author(s) and the source, provide a link to the Creative Commons license, and indicate if changes were made. The images or other third party material in this article are included in the article's Creative Commons license, unless indicated otherwise in a credit line to the material. If material is not included in the article's Creative Commons license and your intended use is not permitted by statutory regulation or exceeds the permitted use, you will need to obtain permission directly from the copyright holder. To view a copy of this license, visit http://creativecommons.org/ licenses/by/4.0/

(C) The Author(s) 2020 